\title{
Zur Geschichte des Partitivs ${ }^{1}$
}

1. Vor zwei Jahren hielt ich auf der Jahresversammlung der Finnisch-ugrischen Gesellschaft einen Vortrag "Über das Objekt in den finnisch-wolgaischen Sprachen" (im Druck erschienen FUF XXXIX 153-213). Darin äusserte ich u.a., dass im Lappischen sowohl das singularische (nur in einigen schwedischlappischen Sprachdenkmälern erhaltene) als auch das pluralische Partitivobjekt ein direktes Erbe der urfinnischurlappischen (= frühurfinnischen) und damit weiterhin der finnisch-wolgaischen Ursprache sei. Wie ich gleichzeitig erwähnte, ist die manchmal gehörte Meinung von der finnischen Herkunft einiger ostlappischer Belege für den Partitiv Singular meines Erachtens schon deshalb unmotiviert, weil "der Partitiv Sg. im s ch hed is chlap p i s c h e n Dialektgebiet grammatisch eine wenigstens ebenso wichtige Aufgabe hat oder gehabt hat wie im Ostlappischen", s. a.a.0. 210. Ich habe meine Ansicht damals noch nicht näher begründen wollen; jetzt dürfte es angebracht sein, auf dieses Thema zurückzukommen.

Auf die morphologische Seite des Partitivs brauche ich nicht einzugehen. Ich beschränke mich auf die Betrachtung einiger Verwendungsweisen des lappischen Partitivs (sein Auftreten als Objekt übergehe ich hier, s. dazu FUF XXXIX 189203), ohne dabei eine vollständige Darstellung aller Belege der verschiedenen Dialekte anzustreben, wodurch mein Ưberblick einen zu grossen Umfang annehmen würde. Zum Schluss konzentriere ich mich auf ein Detail, das auch unter einem weiteren fiu. Aspekt betrachtet von Bedeutung zu sein scheint.

1 Gekürzt und in etwas anderer Fassung als Eröffnungsvortrag gehalten auf der Jahresversammlung der Finnisch-ugrischen Gesellschaft am 2. Dezember 1972. 
2.1.1. Ich behandle zunächst die Fälle des Partitivus loci, d.h. die partitivförmigen $\mathrm{Partikeln} \mathrm{mit} \mathrm{selbständiger}$ lexikalischer Bedeutung, die lokale (selten modale) Adverben - dabei oft auch Postpositionen - sind und die im Satz entweder allein oder (näml. Postpositionen) in Verbindung mit einem anderen Wort als $A d v e r b i a l e$ verwendet werden.

2.1.2. Aus einsilbigen Konsonantstämmen gebildet sind $\mathrm{S}$ nälltie, U nällde, $\mathrm{P}$ nalhte, L nal'te, $\mathrm{N}$ âl'dé 'von oben (Adv.), von - herab (Postp.)' ( fi. yltä); S vuolhtie, U vüelldee, $\mathrm{N}$ ruol'dĕ 'von unten (Adv.), unter (Postp.)' ( $\sim$ fi. alta); N bal'dè, Kld. $B^{i} e \bar{l}^{d} t$, T pie $i l t,{ }_{B} \bar{l}^{d} t$ (Postp.) 'von seiten,

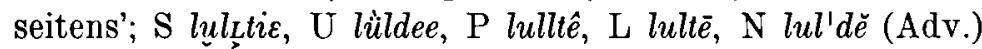
'aus Osten, (dial. auch:) im Osten'. Einen einsilbigen Vokalstamm hat die Postposition $\mathrm{S}$ luhtie, $\mathrm{U}$ lühtee, $\mathrm{P}$ luhte, $\mathrm{N}$ lut'tĕ, luttĕ 'aus der Nähe, (dial. auch:) in der Nähe von etw.' (< fi. luota bzw. späturfi. *lōta).

2.1.3. Die aus zweisilbigen Vokalstämmen gebildeten Partikeln lassen sich in einige Untergruppen einteilen.

2.1.4. Der Stamm einiger Adverben wird von einem Pronomen in Komparativform gebildet: S (Olaus Strphani GraAN in den 1660er Jahren) juoped 'woher, von wo'; kåbbed, kåbbedh id.; tabbedh 'von hier, von dort' = (EliEL LaGercrantz Wb. des Südlp. 174:) Vefs. $\ddot{a} \cdot p p \varepsilon p \varepsilon$ (unübersetzt). Sichere Belege für diesen Adverbtyp sind mir ausserhalb des Südlappischen nicht begegnet.

2.1.5. Es gibt eine Reihe von Adverben, deren Stamm meist ein defektes aber selten ein solches Nomen ist, das ein vollständiges Paradigma besitzt: $\mathrm{U}$ jillèda, $\mathrm{P}$ allêt, $\mathrm{L}$ allēt 'von

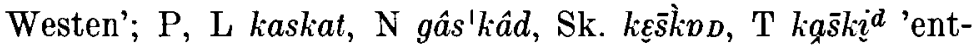
zwei; (dial. auch:) quer durch, zwischen hindurch, dazwischen' ( fi. dial. keskeä 'mitten durch' [s. Arvid GENETz «Suomen

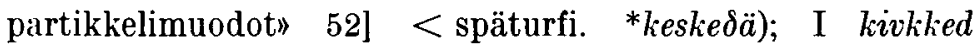
'plötzlich' (< ostseefi. *kiukkada > karel. kiukkoa 'schnell', s. A. OJaJäRvi »Sijojen merkitystehtävistä Itä-Karjalan Maaselän murteissa” 162); S kuhkète, U gühkèda, $\mathrm{P}$ kuhkêt, L kuhkkèt 'aus der Ferne, von weit her'; L kuou'tat, N guow'dât (eigentl. guow'dâd), 'T $k i \bar{u}^{d} t_{t a}^{d}$ 'entzwei (der Länge nach)' 
( fi. kautta 'durch'; die fi. Postposition ist der konsonantstämmige, das lp. Adverb dagegen der vokalstämmige Partitiv von frühurfi. *kavte $>$ fi. kausi 'Periode'); Sk. lü̆ð’̀peD (Adv.) 'breit gewachsen (vom Rentiergeweih gesagt)'; $\mathrm{S}$

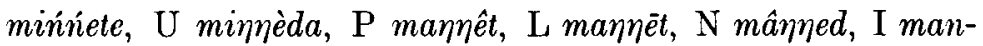
njeed, Sk. män̆nes 'spät; (dial.:) nach; gleich hinter - hervor'

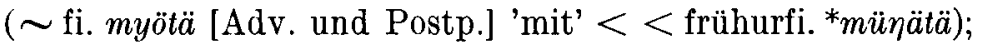
$\mathrm{S}$ nu•urRtădä, U nuor'tada, P norĕhtat, L nuor'htat 'von Norden'; S pijjète, U bijjèda, P paddèt, L padjēt 'von oben'; $\mathrm{S}$ suolete, $\mathrm{U}$ süellèda, $\mathrm{P}$ sóllêt, söllêt, $\mathrm{L}$ suollèt 'heimlich'

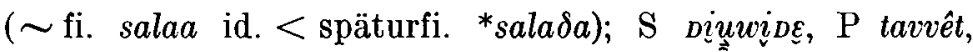
L tavvēt 'draussen vom See'; L tuohkēt 'von hinten (her)'

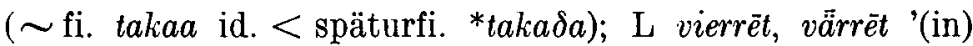

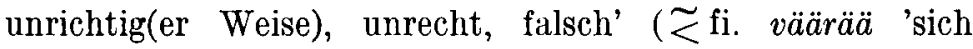
windend; irre, fehl' [s. Elias Lönnro't »Suomalais-ruotsalai-

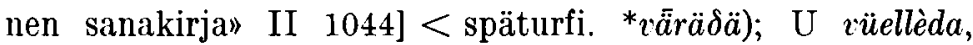
$\mathrm{P}$ vòllèt, L vuollèt 'von unten'; S osok ope , U ulgòda, P ulöküt,

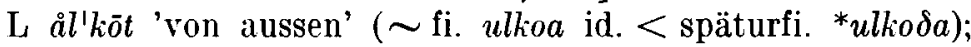
$\mathrm{L}$ aipmèt 'voralters, früher, in alten Tagen'; $\mathrm{S} \breve{u} v \cdot r \cdot j a b \ddot{a}, \mathrm{U}$ àrjeda, P orjāt, L år'jāt 'von Süden'; S (Graan) almed 'ohne', Kld. olme $\delta$ 'öffentlich' (die süd- und kildinlappischen Adverbien scheinen einander lautlich zu entsprechen; auch der Bedeutungsunterschied ist vielleicht nicht unüberbrückbar); L ärrët (Adv. und Präp.) 'abgesehen von, ab-, ungerechnet'.

Wie in zahlreichen anderen Fällen ist es auch hier sehr schwer, eine unbedingt klare Grenze zu ziehen zwischen einem defekten Nomen und einem normalen. Die lulelappischen Adverbien tavvēt und tuohkēt z.B. sind aus defekten Nomina gebildet, nach dem Bild aber, das H. GRundsTröms "Lulelappisches Wörterbuch" vermittelt, wird vom letzteren Wort neben einigen anderen Kasus auch der Nominativ als selbständige Wortform gebraucht (z.B. vārē $t u o h k \bar{e}$ 'das Gelände, der Raum hinter dem Berge'), während vom ersteren Wort ein solcher Gebrauch in diesem Dialekt unbekannt ist (nicht aber beispielsweise im Norwegischlappischen: goggó lae d $\hat{a} v v e$ dām baikest? 'in welcher Richtung ist Norden von hier aus gesehen?'). Ein vollständiges Paradigma besitzt

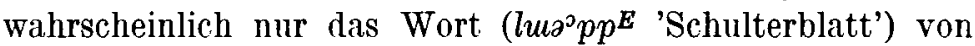


dem das skoltlappische Adverb lü̆ð̆ ’̀pes gebildet ist. - Als Sonderfall sei südlappisch (Graan) quechted, quechtid 'entzwei' erwähnt, dessen Stamm vom Zahlwort für zwei gebildet wird.

2.1.6. Modal-habitive Adverbien, in denen der Endung des Partitivs stets ein suffixaler Labialvokal (urlp. ${ }^{*} \omega$ ) vorangeht, z.B. S bâtrída, P bodnjọd, L pådnjōt, påtnjōt, $\mathrm{N}$ bodnjot (eigentl. bodnjod), I ponnjood, Sk. pońńnD, Kld. pònńó, T pannia 'in verdrehtem, schiefem Zustand' (dies ist von einem zweisilbigen $e$-Stamm gebildet: [N] bodnje 'eine gedrehte Stelle [z.B. in einem Strick]'). Diese Adverbien habe ich ausführlich CIFU 226-255 behandelt, mit der Erwähnung S. 237, dass unter ihnen eine eigene kleine Gruppe solche inari- und norwegischlappischen Formen bilden wie $\mathrm{N}$ gullot (eigentl. gullod), I kullood 'in Gegenwart eines Zuhörers', $\mathrm{N}$ oai'dnot (eigentl. oai'dnod), I oajnud 'in Gegenwart eines Zuschauers', die nur in Verbindung mit dem Genitiv eines anderen Wortes benutzt werden, z.B. $\mathrm{N}$ buokkâi (Gen.Pl.) gullot 'vor aller Ohren'. Hinzugefügt werden muss, dass der letztgenannte Typ - allerdings selten -- auch im Lulelappischen begegnet: mui'htōt $\left(<m u i^{\prime} h t \bar{o}\right.$ 'Erinnerung, Gedächtnis [Fähigkeit sich zu erinnern]' <mui'htèt 'sich erinnern'): $m \bar{u} m$. 'soweit ich mich erinnern, soweit ich zurückdenken kann [ungef. = zu meinen Lebzeiten]', s. Grundström, a.a.O. 530 .

2.2.1. Wie auch aus unserem Beispielmaterial gefolgert werden kann, ist der Partit.Sg. als Partikelform im Schwedischlp. bedeutend lebensfähiger als im Norwegisch- und Ostlp. Teilweise beruht dies auf dem bekannten Prozess, dass nämlich der Essiv in der grossen Mehrheit der lokalen Adverbien besonders im Ostlp. an die Stelle des Partitivs trat, z.B. âl'dě 'von - herab' > I alne; *ol'god 'von aussen' $>$ I olgon. Besonders gross wurde im Schwedischlappischen die Gruppe der unter Punkt 2.1.6. genamnten Adverbien. Grundströms Wörterbuch enthält davon ca. 170, während das Inarilp. über knapp 30 verfügt und das Russischlp. noch weniger aufweist.

2.2.2. Der Partitiv, der uralische Separativ, ist auch im 
Mordwinischen eine allgemeine Partikelendung: aldo 'von unten her, unter', veŕde 'von oben', vasoldo 'aus der Ferne', usw. Die partitivförmigen Adverbien des Lappischen vertreten eine so primitive Bedeutungsgruppe, dass ihre Zugehörigkeit zum ältesten autochthonen Wortschatz der Sprache von niemandem bezweifelt worden ist.

2.2.3. Es ist die Auffassung geäussert worden, dass in den lokalen Partikeln des Südlappischen als Endung des Trennungskasus auch der ursprüngliche Partitiv Plu ra l ( $>$ im Urlp. Akk.Pl.) aufträte, z.B. Vefs. nŭorrtįDE ( $\sim$ nŭork-

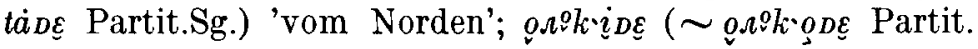
Sg.) 'von aussen', s. Lagercrantz, "Sprachlehre des Südlappischen" 97, Wb. d. Südlp. 95, 107. Wenn diese Erklärung richtig ist (sichere Repräsentanten des Akk. Pl. in diesem Dialekt sind jedenfalls solche Partikeln mit erhaltenem Diphthong in der zweiten Silbe wie Borruitg = ${ }^{*}$ bodoid 'zerstreut'), so kann es sich dabei sogar um Archaismen handeln, die in den anderen Mundarten geschwunden sind. Auch aus dem Finnischen sind mir keine direkten Entsprechungen für sie bekannt, wo es ja sonst recht viel pluralische Partikeln gibt. S. auch Punkt 5.5.9.

3.1.1. Im Lappischen ist - wie auch im Finnischen (vgl. E. N. SetäLä "Suomen kielen lauseoppi»" ${ }^{11}$ 53) - eine Partitivus comparationis-Konstruktion bekannt, deren Partitivteil als Adver bia le im Satz steht.

3.1.2. Partitive von einsilbigen vokalstämmigen Pronomina: L $m$ a $t \bar{e}$ stuorāp, t a $t \bar{e}$ änapuv pårráa 'je grösser (er ist), desto mehr isst er' (hier wie auch in einigen weiter unten stehenden Beispielen aus dem Norwegisch- und Ostlp. tritt die Entsprechung des fi. Adverbpaares mitä - sitä 'je — desto' auf; im L-Dialekt werden neben den Formen matē, tatē solche Varianten verwendet wie mati, matā, tatĕe, tati, deren Vokal der zweiten Silbe sekundär ist); $\mathrm{N} m \hat{a} \not{d} e$ ( $m \hat{a} \not \grave{a})$ gâseb, $d \hat{a} d e(d \hat{a} d \check{e})$ buoreb 'je dicker, desto besser'; I suoppajn lii ta $\not e$ pyereeb, $m$ a de kuhheeb 'das Lasso ist umso besser, je länger (es ist)'; $m u d e$ ( $t u d e, s u d e$ ) vieusab 'stärker als ich (du, er)'; tot olmoož ij lah $k$ e de gin pyereeb 'jener Mensch ist nichts wert' (wörtl. »jener Mensch 
ist nicht besser als jeder beliebigen); ij pastam $t$ a de jienalubon '(das Geschoss) konnte nicht tiefer (eindringen)'; Sk.

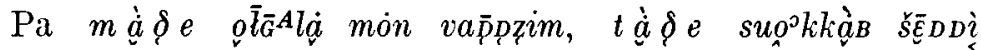
vunū $\bar{D}^{E}$ 'je weiter ich ging, desto dichter wurde der Wald';

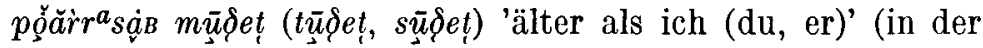
Endungsvariante det begegnet das Partitivsuffix pleonastisch verdoppelt); Nrt. pŭărr ${ }^{a} a^{b} m \bar{o} p e(t \bar{o} p e, s \bar{o} p e)$ id.; $j \bar{\varepsilon} n a^{b} p m \bar{e} p e(t \bar{e} p e, s \bar{e} p e)$ 'mehr als wir (ihr, sie)'; Kld. (G. KerT) jenamp $t \varepsilon d$ 'desto mehr'; T tat $t e$ o.̃gka 'desto weiter'; $t \underset{x}{a} \underset{d}{d} \dot{j e} \dot{a} \bar{m}^{b} p$ 'umso mehr'.

3.1.3. Es gibt auch zahlreiche Fälle, wo die Stämme der Partitivformen mehrsilbig sind. Partitive von Pronomina: Sk. Nrt. $p \check{u} \breve{a r r}{ }^{a} s a^{b} p m^{\circ} \grave{a} n n a^{d} t\left(s^{\circ} \grave{a} n n a^{d} t\right)$ 'älter als wir (sie) beide'; Kld. samjamp $m u$ n ne $\delta$ 'stärker als ich';

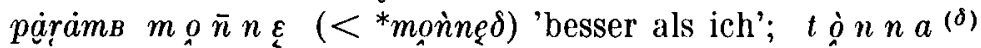
ṣ̌̂r $\overline{r a m}^{b} p$ 'ungeschickter als du'; šs $u_{i}$ reamp $s \bar{o} n$ ne $\delta$ 'grösser

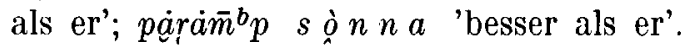

Partitive von Nomina: I $m u$ o $t$ tad čappadub tot ajn-uv lii 'schwärzer als Schnee ist es jedenfalls'; távalii $u k s$ ad

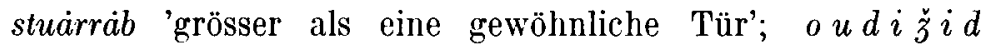
tiervasub 'gesünder als früher' (ooudiž Adj. 'früher, vorherig');

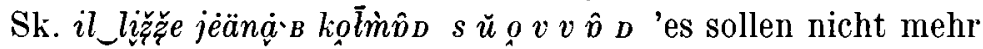
als drei Herde sein'; Kld. u̇ंpsuvvoj illea šu reamp $u \dot{\theta} p-$ s e j j e $\delta$ išluššej ij šu reamp ǐ̆̌es š urre $\delta$ 'der Schüler ist nicht grösser als sein Lehrer, der Diener nicht grösser als sein Herr' (= Matth. 10, 24: Der Jünger ist nicht über seinen Meister noch der Knecht über den Herrn); puireamp la $m$ p$s e_{i} t$ t $e \delta$ 'besser als ein Schaf'; jiñk ijja lea šuireamp $p \bar{o} r m u s ̌ s ̌ \delta$ 'ist nicht das Leben mehr denn die Speise' (Matth. 6, 25); ienamp kirj-kījij i farisejij $v u j k$ e $\delta v \bar{u} t$ t e $\delta$ 'mehr als die Gerechtigkeit der Schriftgelehrten und der Pharisäer' (= Matth. 5, 20: es sei denn eure Gerechtigkeit besser als der Schriftgelehrten und Pharisäer); ńuөizeamp ¿ $\check{c} \check{e} \boldsymbol{e} \delta$ es '(sie waren) böser als er selbst' (hier haben wir ein seltenes Beispiel, wo an die Endung des Partitivs noch das

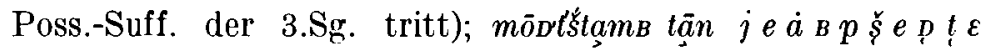
'schöner als dieses Pferd'; (A. EndjukovskiJ) jogk vulga $n i \mathfrak{i} \cdot \boldsymbol{m}$ e d t e šanta 'der Fluss sank unterhalb des Uferhangs'. 
3.2.1. Der Partitivus comparationis ist im Ostlp. viel melnr in Gebrauch als in den Dialekten des Westlp., die den Partitiv nur in der je - desto-Konstruktion zu kennen scheinen. Wie aus der Darstellung von K. B. WIKLUND in Le Monde Oriental VII (1913) S. 227-229 hervorgeht, ist die Entsprechung für die Konstruktion $\operatorname{lp} \mathrm{N}$ mâdĕ - dâdĕ im Schwedischlp. nicht nur im Lulelp. sondern auch in den Dialekten von Arjeplog und Malå belegt. Im "Manuale Lapponicum" des Johnswes Tonnzus aus d.J. 1648 begegnet der Partitivus comparationis sowohl von Pronominal- als auch von Substantivstämmen, z.B. tatte nuorapog '(die Zweijährigen und) Jüngeren als diese'; $t$ a $t$ t e puorreput 'desto besser'; $j$ u $t$ te kuckepo orro, t a t te stuorrepo schiadta 'es wird je länger je grösser'; karrasepo i a bmemet 'bitterer als der 'Tod', s. J. Qvigstad MSFOu LXVII 342, 345. Zumindest das letztgenannte Beispiel wird T. von einem ostlappischen Gewährsmann erhalten haben.

3.2.2. Einige ostlappische Dialekte kennen auch einen p l u r a l i s c he n Partitivus (vom Standpunkt der hentigen Sprache betrachtet: Accusativus) comparationis, z.B. I oaivis kuhheeb e ärasijd '(Saul war) um seinen Kopf grösser als die anderen'; sij--pillešuvvii e $i j i i d i z-u v$ (Akk.Pl. + Poss.-Suff. 3.Pl. + Anhängepartikel) nieyribin 'sie - - wurden noch schlechter als ihre Väter'; Kld. ro iñ $_{k}$ ijja leä šu reamp as $g i j t$ ? 'ist nicht der Leib mehr denn die Kleidung?' (Matth. 6, 25); vaj tij liepped čevta puireamp s $i$ e $n i j t$ ? 'seid ihr denn nicht viel mehr denn sie?' (Matth. $6,26$.

Bei der Datierung des lappischen Partitivus comparationis darf nicht übersehen werden, dass diese Konstruktion sowohl im Ostseefi. als auch im Mordwinischen begegnet (z.B. kize te le de paro 'der Sonmer ist besser als der Winter'), so dass sie im Frühurfinnischen als Erbe der fi.-wolg. Zeit auftrat.

4.1.1. Als nächste Gruppe soll die Verwendung des Partitivs als Form des Beziehungswortes einer Postund Präpositi o n behandelt werden.

4.1.2. Der Partitiv ist aus einem einsilbigen Pronominal- 
stamm gebildet: P t a $t$ e mañnêl 'hernach, später'; L $t$ a $t e$ ( $t$ a $t$ a-)mil'te 'je nachdem; wieder, wiederum; im selben Augenblick, gerade da; (sofort) darauf, sogleich danach'; $t \bar{a} t a-(t \bar{a} t \bar{a}-) m i l ' t e$ 'hier hinaus, diesen Weg (dahin), hier; sogleich, jetzt gleich, jetzt sofort; (sogleich) hernach, hiernach' (neben den in ihren Vokalverhältnissen regelmässigen Formen tatē, *tātè oder an ihrer Stelle begegnen im L-Dialekt die sekundären Formen tatā, tāta, tātā, vgl. 3.1.2.); $\mathrm{N} d \hat{a} d e$

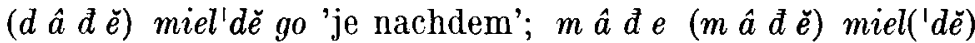
id.; I ovdil t ä $d e$ 'vor dem'; eereeb ta $d e$ ( $t \ddot{a} \ddot{a} \ddot{d} i, t u \ddot{d} e$ ) 'ausser dem (diesem, dir)', z.B. kalhan eereeb tude lijjii kullamin 'es waren doch ausser dir noch andere, die hörten'; $m a d e$ vàràs 'wozu'; $m u d e(t u d e, s u d e)$ varass 'für mich (dich, ihn)', z.B. tude vàräshan mun tom puohtim 'für dich habe ich es doch gebracht'; vääldi t a de mield(i) ko rutta pišta 'nimm (Ware) danach, wie das Geld reicht'; $t$ a de verrin od. t. väras 'dafür', z.B. tade verrin-u(v)ks mun adelim tunjin ruudajd? 'habe ich dir denn etwa dafür das Geld gegeben?'; $t$ a de vuasti 'dagegen'; NB noch die Redewendung madegin maajeeb 'nach einer Zeit, in Kürze' (z.B. jas mun liččim tuojbad m.m. 'wenn ich doch bald genesen würde'), von der man schwer sagen kann, ob sie hierher gehört oder zu Punkt 3.1.2. (madegin = Partit. von mii 'was' + Anhängepartikel gin 'auch, ja; auch nicht, nicht

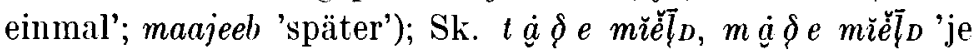
nachdem'; Kld. $t \bar{a}_{i} \delta$ mìlt 'demnach, deswegen'; $t \bar{a}_{i} \delta$ go ${ }_{i}$ rrèn 'von hier'; $t u_{i} \delta\left(t u_{i} \delta\right.$ ') go ${ }_{i}$ rrèn 'von dort'.

4.1.3. Die Stämme der Partitivformen sind mehrsilbige Sub-

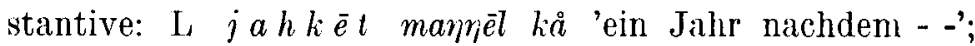

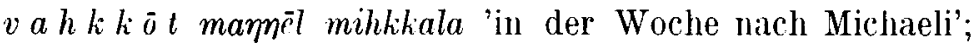
ja $h k \bar{e} t$ å $u^{\prime} t a l$ 'ein Jahr früher'; I ä $j g i d$ mield(i) 'mit der Zeit'; a n e mad (eine Form des westlichen Dialekts des Inarilappischen $<$ a n e $m i d$ ) varáshan tot lii rahtum 'das ist ja zur Verwendung (zur Benutzung) gemacht'; vuolgij ijjad vuasta vyeijid '(er) fuhr in die Nacht hinein weg'; $k y e h t l u v$ kerisid maneh syeinih täälvist $k u s s$ ad ruasta'zwanzig Schlittenfuhren Heu gehen im Winter auf eine Kuh'; s e $j$ n $i d$ vuástá 'gegen od. an die Wand'; sun moonaj toumbel $v \ddot{a} \ddot{a} r r i d$ 
'er ging auf die andere Seite (nach jenseits) der Anhöhe'; ulguubeln $t$ up p e ed 'ausserhalb der Stube'; Sk. kŭ̌̄ $\bar{x} t$ val

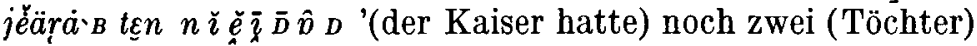

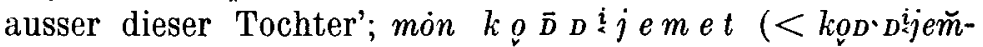
mes) vaijj $j^{p} \bar{\varepsilon} n \dot{a} m$ 'ich schufte mich halbtot' (wörtl. "ohne

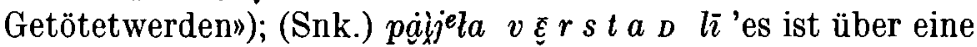

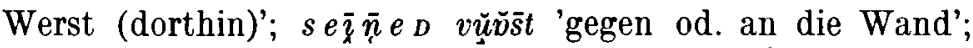

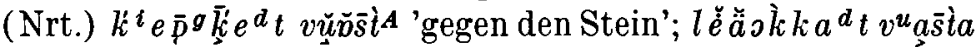
'an das Rückenbrett des Lappenschlittens'; tsëälkam sänë $s \dot{a} n n e^{d} t v^{\prime} \tilde{s}^{A}{ }^{A}$ ich sage ein Wort gegen ein anderes Wort (= ich bleibe die Antwort nicht schuldig)'; Kld. a $a_{i} l t$ Galile $j$ $m i$ er $r$ e $\delta$ 'nahe des Galiläischen Meeres'; kŭa $\bar{u}^{d} t a \quad s \dot{a} \bar{l}{ }^{d} t$ te $\delta$ 'mitten auf dem Fussboden'; $k \bar{u} l \bar{\imath}$ mun' $m \bar{\imath} l l$ e $\delta$ mìlt'- der mir gefällt' (wörtl. »-- der meinem Sinn gemäss ist»);

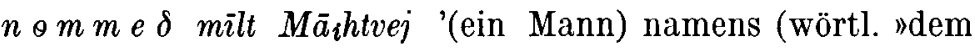

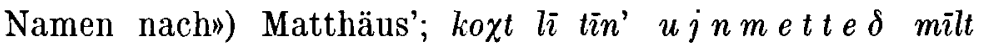
'wie ist es eures Erachtens?' (wörtl. "ihrer Ansicht nach"); $v u \partial \bar{s} t^{A} m \bar{u} r r p \delta$ 'gegen od. an den Baum'; veşt stienn ne $e^{\delta}$

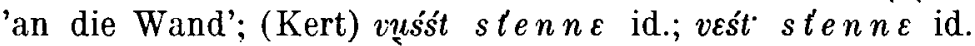

4.2.1. Der in Verbindung mit Post- und Präpositionen gebrauchte Partitiv ist, wie auch der Partitivus comparationis, heute in der Hauptsache eine ostlappische Erscheinung, aus welchem Grunde ihn einige Forscher als Fennismus haben erklären wollen. KNUT BERGSLAND hält eine solche Annahme nicht für unumgänglich (vgl. Studia Septentrionalia V 55), bemerkt jedoch, die mit dem Partitiv stehenden Postpositionen lpSk. (Nrt.) vas̄ta, vas̄ìt 'gegen' hätten "finnischen Vokalismus» (a.a.O. 54). In Wirklichkeit zeigen die betr. Formen einen durch schnelles Sprechtempo in der schwachbetonten Partikel verursachten unregelmässigen Wandel $u p, u a>a$ (aus demselben Grunde konnte im Kildinlp. im diesbezüglichen Wort die Entwicklung $u ә>\dot{a}$, $\varepsilon, \quad e$ bzw. $u$ eintreten); der im Ergebnis entstandene Monophthong ist durch einen blossen Zufall identisch mit dem Vokal der ersten Silbe in den fi. Partikeln vastaan, vasten. Ferner muss betont werden, dass die Verbreitung der pronominalstämmigen Partitive dâde (*dâtte), mâde (*mâtte) in diesen Konstruktionen unbestreitbar gemeinlappisch ist und 
dass die ostlp. Konstruktionen, denen man finnische Herkunft zuschreiben will, auch im Lulelappischen eine deutliche Ent-

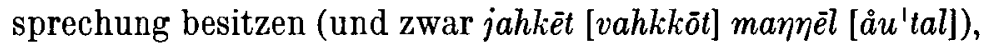
dem die unter Punkt 2.1.5. und 2.1.6. genannten zahlreichen und vor allem für diesen selben Dialekt typischen partitivförmigen Adverbien einen natürlichen Hintergrund zu geben scheinen. Es erhebt sich die Frage, ob die Fennismus-Erklärung als allgemeins Prinzip noch realen Boden behält, auch wenn einige Einzelfälle am besten als Lehnübersetzungen verstanden werden könnten. Die ostlappisch wirkenden Partitivkonstruktionen im Manuale von Tornæus, ja $b \mathrm{me}$ m e $t$ wuosta 'dem Tod entgegen', cuohte c u o h t e t wuosta ja ahte a h t e t wuosta 'zwei gegen zwei und einer gegen einen', dürften kaum mehr als chronologisches Interesse haben. (Zu diesen Konstruktionen s. Qvigstad, a.a.O. 342.)

4.2.2. Partitivrektion begegnet bei Postpositionen nicht nur im Osfi., sondern auch im Mordwinischen und gerade dort bei den Bedeutungsentsprechungen der lulelp. temporalen Post-

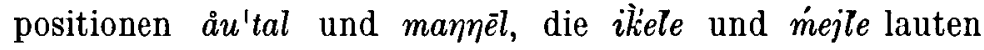

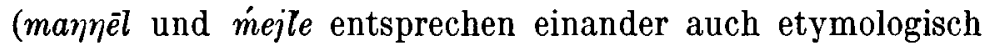
genau [<*münälä]), z.B. śe škado mejle 'nach dieser Zeit'. Mit dem Ablativ-Partitiv steht ausser diesen die mordw. Postposition baškia 'ausser', desgleichen auch deren Synonym im Finnischen (paitsi: p. minua 'ausser mir') und Ostlp. (Sk. $j \tilde{e} \ddot{a} r \dot{a} \cdot{ }_{B}: j . t \varepsilon n n i \overline{e q} \bar{D} \hat{b} D$, s.o.). Somit besteht kein prinzipielles Hindernis für die Möglichkeit, dass der lapp. Partitiv auch in diesen Konstruktionen bereits auf die fi.-wolg. Ursprache zurückgeht.

4.2.3. Es gibt einige Fälle, wo das Beziehungswort der Post- oder Präposition auch im Akkusativ P l u r a l (< Partit.Pl.) steht, z.B. I $p \dot{a} r n \dot{a} \dot{a} j d$ (Akk.Pl.Dim.) vuásta 'schwanger' (wörtl. "gegen Kindchen"); Sk. Snk. oū $D v \Omega$ $k \bar{o} \wedge m \eta_{i} \quad s \bar{u} t k i{ }_{D}$ 'innerhalb von drei Tagen'; öupeB

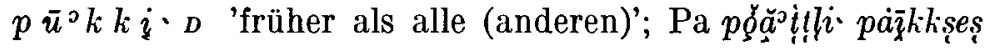
$\bar{o}^{u} d^{i}-b^{i} e l n v i \cdot l l \bar{e} s$ (Akk.Pl. + 3.Sg. Poss.-Suff.) 'er kam vor (wörtl. "auf der Vorderseite») seinen Brüdern nach Hause'. Die Tauglichkeit des letzten Beispiels kann allerdings in Frage gestellt werden, da die diesbezügliche Akk.Pl.-Form 


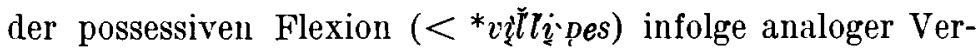
allgemeinerung in dem Dialekt auch die Funktion des Genitivs erhalten hat, so dass wir nicht wissen können, ob im untersuchten Satztypus das Beziehungswort der Präposition v o r dem genannten Prozess der Verallgemeinerung der Form nach ein Akkusativ-Partitiv war oder ein Genitiv. J. Beronka ("Lappische Kasusstudien" 164) nennt die Konstruktion Präp. + Akk.Pl. u.a. aus dem seelappischen Dialekt von Kalfjord: gasskal bordid 'unter den Speisen', doch muss dieses Beispiel (wie auch das in derselben Sprachprobe erscheinende gasskal mu oraid 'zwischen den Bäumen') als nicht beweiskräftig abgelehnt werden, da der in Frage stehende Dialekt recht weitgehend einen solchen Typus darstellt, wo der Akk.Pl. sogar der absoluten Flexion die Funktion des Genitivs übernommen hat, z.B. $d u$ č or vid (Gen. Pl. < Akk.-Partit.Pl.) alli 'auf deine Hörner'. Die Formen bordid und muoraid in unseren Belegen haben somit an die Stelle früherer Gen.-Pl.-Formen (bordii, muorâi) treten können. Nicht viel sicherer sind die Fälle, die Beronka aus dem seelappischen Dialekt von Maattivuono anführt, aiřra

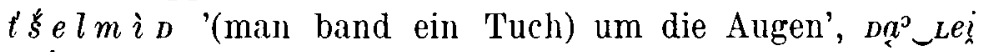

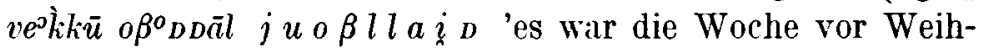
nachten', denen man noch hinzufügen könnte Birrra G $\hat{e} \delta_{G} i{ }_{D}$ 'um die Steine', sirrra muora i D 'um die Bäume', denn obwohl sich der Gen.Pl. in dieser Mundart oft vom Akk.Pl.

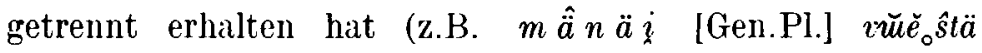

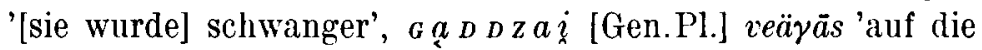
Nägel gestützt (d.h. mit den Nägeln])', finden sich in den Texten doch recht zahlreiche Fälle, in denen sich der Akk.Pl. — wie im Dialekt von Kalfjord - auch im Genitiv durchge-

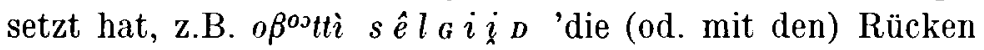
gegeneinander'; e le $m m \ddot{a} i D$ meńts 'hinter den Männern

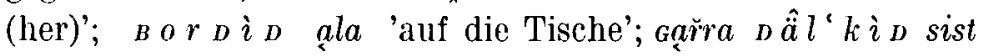
'während der Gewitter'.

4.2.4. Es kann kein Zweifel daran bestehen, dass in den Post- und Präpositionskonstruktionen der lappischen Dialekte das Beziehungswort im Partitiv in gewissem Umfang vor dem im Genitiv gewichen ist. Und doch bezieht Beronka 
in seiner Arbeit über die lappische Kasussyntax meines Erachtens zu einseitig den Standpunkt (vgl. a.a.O. 214), der Partitiv sei ohne weiteres dann ursprïnglich, wenn el im Finnischen und Ostlappischen als Entsprechung des westlappischen Genitivs auftritt, z.B. fi. seinää rasten, lpI sejnid vuasta $\sim \operatorname{lpN}$ seine ruos'ta(i) 'gegen od. an die Wand'. Das parallele Auftreten bzw. die gegenseitige Konkurrenz von Partitiv und Genitiv kann in manchen Fällen bedeutend älter sein als die Zeit der Sonderentwicklung der lp. Mundarten. Gibt es doch auch im Fi. eine ganze Reihe von Post- und Präpositionen, die sowohl mit dem Genitiv als auch mit dem Partitiv konstruiert werden: edcllä 'ror', keshellä '(in)mitten', likellä bzw. lähellä 'nahe. in der Nähe', puolella (sisäp. 'auf der Innenseite, innerhalb', täll ï $p$. 'diesseits', ulkopuolella 'ausserhalb'), puolen (tuolla p. 'jenseits'), vastapäätä 'gegenüber', ympäri 'um, herum', usw. Mit einer solchen Doppelheit können sich auch semantische Differenzen verbinden. Z.B. juoksi turan ympäri bzw. j. ympäri tuvan bedeutet entweder, dass jemand in einem kleinen Gebäude mit einem Raum dieses Zimmer rundherum ablief oder aber, dass er aussen um dieses Gebäude herumlief, während juoksi ympäri tupaa lediglich aussart, dass er innerhalb des Gebäudes ständig herumlief. Auch in den Postpositionskonstruktionen des Ostlappischen beobachten wir fortwährend diese selbe Doppelheit in der Form des Beziehungswortes: IpI otdil täde (Partit.) 'vor dem' iyve (Gen.) ovdil 'ein Jahr früher'; Kld. prōrokij sārnmuššs (Partit.) mïlt 'nach der Rede der' Propheten' sijje leańč Isajja prorok sārnmuž (Gen.) mīlt 'es geschehe ihnen nach der Rede des Propheten Jesaja';

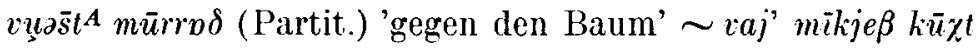
$u_{i} c c$ lonta out mivv teañga (Gen.Dim.) vuesta? 'werden (nicht) zwei Vögelchen für ein Scherflein verkauft?', usw. Die Klärung der Entwicklungsgeschichte der Rektion bei den ostlp. Post- und Präpositionen wäre eine wichtige, aber gleichzeitig anspruchsvolle Aufgabe. Zu diesem Zweck müsste aus dem Russischlappischen noch reichlich vielseitiges weiteres Material gesammelt werden, dessen Analyse sicher nicht nur ergeben würde, dass die rezessive Tendenz des 
Partitivs weiter fortschreitet (welcher Trend z.B. im Dialekt von Akkala [Babino, Babinsk] im Lichte der Texte von Genetz sehr klar ist), sondern auch feine Bedeutungsunterschiede zutage brächte, die mit der Gegensätzlichkeit von Partitiv und Genitiv verbunden sind.

4.2.5. Es dürfte eine allgemein akzeptierte Auffassung sein, dass die ursprünglichen Kasus der Beziehungswörter der fiı. Postpositionen der Nominativ und der Genitiv sind, während die den Partitiv verlangenden Post- und Präpositionen ursprünglich Adverben waren. Ihre Beziehungswörter waren entweder Trennungskasus-Adverbialbestimmungen (z.B. fi. tuolle puolen va ara a, lpI toumbel[e] $v \ddot{a} \ddot{a} r r i d$ 'nach jenseits der Anhöhe'; das partitivförmige Glied dieser Konnexionen bedeutete ungefähr "weg von der Anhöhe») oder Partitivobjekte (z.B. fi. kulki t i e t ä pithin 'er ging den Weg entlang', wo die Postposition pithin die adverbiale Bedeutung 'in die Längsrichtung' hatte; desgleichen gliederte sich juoksi ympäri tupaa ursprünglich »er lief die Stube [Obj.] umher [Adverbiale]"). Vgl. z.B. Verf., "Kieli ja sen tutkimus" 230, 323-324. Der Trennungskasus-Charakter des partitivischen Beziehungswortes der Postpositionskonstruktionen kommt auch darin zum Ausdruck, dass der Partitiv oft wechseln kann mit einem in der Gegenwartssprache produktiven Trennungskasus, dem Elativ, und das sowohl im Lappischen (z.B. I toumbel[e] vä̈̈rrid s.o. toumbel[e] vä̈ariist [Elat.] id.) als auch in den finnischen Mundarten (s. z.B. Eino Suova Vir. 1938 S. 114--118).

5.1.1. Eine ausgedehnte und vielseitige Verwendung besitzt der Partit.Sg. als Kasus des A t t r i b ut s. Es ergeben sich mehrere Typengruppen.

5.1.2. Wir untersuchen zunächst die Fälle, in denen auch das Beziehungswort im Partitiv steht und m.a.W. eine vollständige Kongruenz herrscht zwischen Beziehungswort und Attribut.

5.1.3. Zunächst begegnet in den das südlappisch-umelappische Dialektgebiet vertretenden Texten von Olaus Graan ein von einem einsilbigen Pronominalstamm gebildetes Attribut: sii utzsin d a t te maned 'die suchten dieses Kind'; kiggidh ta te maanadh 'erkundigt euch nach diesem Kind'. 
Genetz hat aus dem Dialekt von Kildin einen Satz, wo ein Pronominalattribut mit dem nachfolgenden Substantiv kongruiert und diese beiden zusammen ein Attribut des Partialwortes (s. unten Punkt 5.5.) bilden: $t$ e $\delta$ olmńe $i t t e \delta$ ij ienney (Partialwort) lea 'diese Menschen (eigentl. Singular) gibt es nicht viel'.

5.1.4. Das aus mehrsilbigen Wörtern gebildete Partitivattribut tritt in den einzelnen Dialekten etwas unterschiedlich auf.

Graan bringt einige Belege für ein mit dem Partitivobjekt kongruierendes Adjektivattribut: anum $k$ a $i k$ ed wecked 'ich flehe um alle Hilfe'; die det wainud--äckehien puered jelemet 'jetzt will er - - ewiges gutes Leben'.

Der als Adverbiale stehende Partitivus comparationis kann ein kongruierendes Zahlwort-Attribut haben. Ein Beispiel hierfür ist der schon oben unter Punkt 3.1.3. genannte skolt-

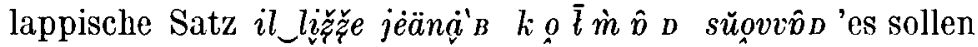
nicht mehr als drei Herde sein'.

Aus dem Inarilappischen hat A. V. Koskimies 1886 Wendungen aufgezeichnet, in denen der als Attribut stehende Partitivus mensurae (zu diesem Begriff s. Setälä, a.a.O. 53) ein kongruierendes Zahlwort-Attribut besitzt: o htad (kyehtid, kulmad) suormad oolas 'das ein (zwei, drei) Finger dicke Rückenfett' (wörtlich »Rückenfett von einem Finger [zwei, drei Fingern]").

5.2.1. An den in Abschnitt 5.1. genannten Fällen schliesst sich ein Typus, wo das Beziehungswort des Partitivattributs im Elativ steht.

5.2.2. Das von einsilbigen Pronominalstämmen gebildete Partitivattribut ist an den beiden Enden des langgestreckten lappischen Sprachraumes am stärksten vertreten, fern im Westen und weit im Osten: $S$ (Røros) $d \ddot{a} h t i e$ goåtasta 'aus dieser Hütte'; (Graan) iuek - purre dat te leibist 'der - - dieses Brot isst'; P vurhkest muni ai t a te vinast 'heb auch mir von diesem Schnaps auf'; L $m$ a $t$ neitas 'von welchem Mädchen'; t a $t$ müöras 'von diesem Baum' (weitere lulelappische Belege liefern die Partitivformen der Pronomina tāt 'dieser', tuot 'jener dort' und tắt 'jener, jener dort'); Kld. te $\delta^{\prime} \quad p \bar{a}_{i}$ lest 'von dieser Zeit an'; te $\delta$ ' vuirest 'in dem 
Augenblick; $\quad \boldsymbol{t} \bar{a}_{i} \delta$ ' päjkest 'an diesem Ort'; T $t a_{i} d e$ iøjest 'an diesem Bach'.

5.2.3. Die aus mehrsilbigen Stämmen gebildeten Partitirattribute repräsentieren verschiedene Wortarten. Adjektive: $\mathrm{S}$ (Graan) monum tdon aii katte / Jegedh pueredh armost 'behüte mich auch aus deiner guten Gnade'; $a u d e b u$ l (Kompar.) aimust 'aus der früheren Welt'.

Zahlwörter: S (Roros) gektára goåtasto 'aus zwei Hütten'; (Graan) ulkus wueiieti Jesus pergelem a chtedh nialmetemest 'Jesus vertrieb den 'Teufel aus einem Stummen'; $\mathrm{P}$ k a k $c \bar{e} t$ olobmast son i palača 'er fürchtet acht Männer nicht'; L $k$ å $l m$ å $t$ par'nés 'von drei Jungen'; Kld. $\theta \chi \iota$ e $\delta$ la innest 'aus einer Stadt'; mañna $k u t$ te $\delta$ piejvest 'nach sechs Tagen'.

Pronomina: S (Undersåker) kusktane kijä̈ln šteärata $k^{\circ}$ a $p$ pa $i k \dot{e} j$ i t ie coarvis̀te '(er) klammert sich mit beiden Händen an beide Hörner (des Elches)'; L $k$ å $p p \bar{a} t$ pielēs 'von welcher Seite'; $k$ a l l $\bar{e} t$ härēs 'aus wievielen Richtungen'; $m$ å $\mid t \bar{e} t$ par'nēs 'von vielen Jungen'.

5.3.1. Auf das Auftreten des Partitivattributs vor einem Beziehungswort im Elativ ist in verschiedenem Zusammenhang aufmerksim gemacht worden, rgl. Petrus FuellSTröм "Grammatica lapponica" 45; Wiklund, "Laut- und Formenlehre der Lule-lappischen Dialekte» 212-213, JSFOu X 207-208, "Lärobok i lapskil sprâket" ${ }^{2} 40,53-60$; IGNác HaLíSz "Svéd-lapp nyelv" VI S. XXVII, XXX; Lagercrantz, "Sprachlehre des Südlappischen" 36, 90, 93, "Sprachlehre des Westlappischen" 111; Beronka, a.a.0. 116, 214; Bergsland, "Røros-lappisk grammatikk" 110, 263-264, Studia Septentrionalia V 32-33; Grundström, a.a.0. 1835, 1841-1843; PaAvo Ravila Sananjalka 2 S. 32; Verf., CSIFU I $204-$ 205, 207; K. Kost ibid. 281_282; Raija Bartexs MSFOu 148 S. 158.

Durchaus glaubwürdig ist die Auffassung von Beronka und Ravila (a.a.O.), dass das einem Beziehungswort im Elativ vorangehende Partitivattribut ein Relikt aus einer Zeit ist, wo der Partitiv noch der allgemeine (also auch zur Flexion der Substantiva gehörende) Trennungskasus war. Auch im 
Richtungs- und Ruhekasus hat lappischerseits nur das Attribut den ursprünglichen Flexionstypus beibehalten. Die Konstruktion Partit. + Elat. kann im Lappischen nicht finnischer Herkunft sein, wie ihr Verbreitungsgebiet zeigt und vor allem die Tatsache, dass eine entsprechende Konstruktion im Osfi. überhaupt nicht bekannt ist.

Die Punkt 5.1.3. und 5.1.4. untersuchte Konstruktion Partit. + Partit. dagegen ist natürlich in der osfi. Syntax allgemein, doch berechtigt dies noch nicht, finnischen Einfluss für das Lappische anzunehmen. Wenn als wahrscheinlich nachgewiesen werden kann, dass die Partitivförmigkeit der in den lp. Sätzen als Beziehungswort stehenden Glieder eine autochthone Erscheinung ist, so ist an einem mit seinem Beziehungswort kongruierenden Attribut nichts Befremdliches, deun die Kongruenz des Attributs war ganz offensichtlich im Iappischen ursprünglich weiter verbreitet als normalerweise vermutet, val. Verf., a.a.O. 205-207; Bartens, a.a.O. 155-160. Die $11 \mathrm{~m}$ zu behandelnden 1p. Partit. + Partit.-Fälle sind solche, wo das partitivische Bezugswort entweder das Objekt ist oder ein Partitivus comparationis oder ein in Verbindung mit einem Partialwort auftretender Partitivus totius, deren aller Eigenständigkeit über jeden Zweifel erhaben ist. Die einzige Konstruktion, deren Echtheit ich nicht durch Beweisstücke zu motivieren vermag, ist

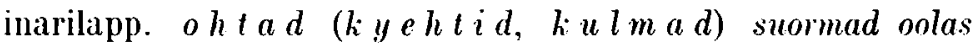
(Punkt 5.1.4.). Hierauf komme ich Punkt 5.4.4. zurück.

5.3.2. Die pluralische Entsprechung der Punkt 5.1.3. und 5.1.4. erwähnten Konstruktion, Akk.Pl. + Akk.Pl. (< Partit.Pl. + Partit.Pl.) ist in einigen Fällen gemeinlappisch. Vor allem zu nemmen sind die Satztypen (lpN) son oinii $d \bar{a} i d$ boc'cuid 'er sah diese Rene', mâ $i d$ boc'cuid son öiniı? 'welche Rene salı er?', wo die determinativen bzw. interrogativen Pronomina als Attribute stehen. Bekannt ist auch die Kongruenz des Wortes buorre 'gut': bririd boc'cuid usw.

Die inarilappische Voll- oder Halbkongruenz des Attributs, die in Verbindung mit einem Partitiv und auch anderen Kasus auftritt, ist zumindest nach meinen Exzerpten zu- 
sätzlich zu den im vorangehenden Kapitel genannten Pronomina die Regel zunächst einmal dann, wenn als Attribut die Indefinitpronomina kallaad 'der wievielte?; (Pl.) viele', mottoom 'irgendein; (Pl.) etliche', nubbe 'ander' und seämmäa 'der-, die-, dasselbe' stehen. Belege für die Konstruktion Akk.Pl. + Akk.Pl.: eereeb täăj sun oă̌uj kal a $d i j d$ eres pakkumijd 'ausser diesen bekam er mehrere andere Gebote'; mun-uv äaigum motomijd poccujd vyebdid 'auch ich beabsichtige, einige Rene $\mathrm{zu}$ verkaufen'; sun vuolgatij $n u u b b i j d$ palvalijjejd 'er schickte andere 1)iener'; Heärra čaalij táaid tavluuid $s$ e ä $m m \dot{a} j d$ saanijd 'der Ilerr schrieb auf diese Tafeln dieselben Worte'. Zweitens ist die Kongruenz in diesem Dialekt charakteristisch für Adjektive, denen die undeklinierbare attributive Form fehlt, jene lappische Sonderentwicklung, vgl. Verf., CSIFU I 206. Obligatorisch ist die Kongruenz Akk.Pl. + Akk.Pl. der in diese Gruppe gehörenden Adjektivattribute dann, wenn es sich um ein im

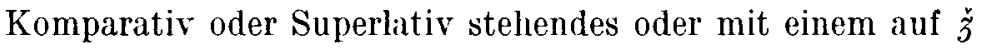
endenden Diminutivsuffix gebildetes Adjektiv handelt, z.B. u cebijd (< ucceeb 'kleiner') kaandajd 'kleinere Jungen'; jo te l umosijd (< jotelumos 'schnellst') eergijd 'schnellste Renochsen'; $t i j m \dot{a} \dot{a} j d$ (< tïmä $\check{z}$ 'vorjährig') liuossijd 'vorjährige Gäste'. Bei anders gearteten Adjektiva zeigt die Kongruenz die selbständige Stellung des Attributs an, seine psychologische Relevanz, während mangelnde Kongruenz bedeutet, dass das Attribut nicht besonders hervorgehoben wird. Mit diesen Voraussetzungen kann die Kongruenz zunächst einmal in Adjektiven auftreten, die überhaupt keine undeklinierbare attributive Form haben. Solche sind u.a. pase 'heilig', puoh 'all', pyeri 'gut', nabdem 'solch(er)', ferner die adjektivisch verwendeten Partizip Präsens-Formen der Verben (von den letztgenannten können zwar einige mit Sonderbedeutung mit der Attributendung $s$ versehen auftreten), usw. Z.B. sij tiettii nabdemijd tuoddarijd, ete kost kodeh assii 'sie wussten solche Fjälle, wo sich wilde Rene aufhielten'; tobbeen mun čáaitàm tiijan puohajd apiidan 'dort zeige ich euch alle meine Kräfte'. Zweitens können als Attribute auch solche Adjektive kongruieren - und hierher 
gehört die überwiegende Mehrheit der Adjektive --, die als nichtmarkierte Attribute in der auf verschiedene Weisen gebildeten undeklinierbaren attributiven Form stehen. - Für einige Akk.Pl. + Akk.Pl.-Konstruktionen finden sich alch Beispicle bei Bartens, a.a.O. 160.

Vorläufig habe ich keine Gelegenheit gehabt, die Kongruenz des Adjektivattributs im Russischlappischen auch nur anhand des schon gesammelten Materials zu erforschen, geschweige denn diesbezügliche Untersuchungen im Terrain durchzuführen, was an sich eine überaus wichtige Aufgabe wäre. Doch sind mir aus diesen Dialekten u.a. einige Akk.Pl. + Akk.Pl.Konstruktionen aufgefallen, die zeigen, dass es auch hier zumindest deutliche Spuren gibt von einem System, das dem im Inarilappischen herrschenden gleicht, z.B. Sk. Pa k $u \bar{\chi} i \underline{i} \cdot D$ kuozzi⿱口 $(=\mathrm{I}$ kuohtujd kuozzajd, $\mathrm{N}$ guk'tuid guosâid) 'beide Fichten' (< Sk. kū̄th , I kuohtuuh, N guk'tuk,

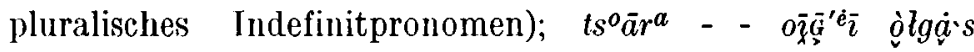

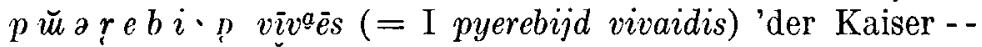
stiess seine besseren Schwiegersöhne hinaus'; Kld. $p \bar{u} k i j t$ kioplajt (= I puohajd pyeccejd) '(Jesus heilte) alle Kranken'.

Ein wichtiger Beweis für die alten ostlappischen Wurzeln des inarilappischen Systems sind die Akk.Pl. + Akk.Pl.-Fälle des ehemaligen Dialekts von Sodankylä. Sie begegnen (vgl. Setälä, JSFOu VIII 116-117) in einem von JoHaxNes SchefFer in seinem Werk "Lapponia" 1673 veröffentlichten Gedicht, das von Oraus Sirma stammte, einem Sprecher des genannten Dialekts; es sind folgende: Mack quodde - poorid ronaidh 'die gute grüne (Äste) tragen' (hier kongruiert also das Wort buorre 'gut'); $K u l c k e d h$ (= I kolgejd) palvaid - - Suuttetim 'den schwebenden Wolken bin ich gefolgt' (es kongruiert das adjektivisch verwendete Partizip Präsens); Morredabboid - päiwidad, linnafabboid - Salmidadd, li eg $\ddot{a} \int a b b$ o $i d$ waimodadd 'deine schönsten Tage, deine mildesten Augen, dein wärmstes Herz' (hier konqruieren die komparativischen Adjektive; die Pluralität der von den beiden letzten Wörtern gebildeten Konnexion ist unlogisch und geht auf den Einfluss der vorangehenden Zeilen zurück). 
5.4.1. Selten ist dic Konstruktion Partit. + Iness. Vorläufig kenne ich dafür nur einen Beleg aus dem zur südlichen bzw. torniolappischen Gruppe des Norwegischlp. gehörenden Dialekt von Griatangen: т $a_{\text { }}$ i $\varepsilon$ râjicn 'seitdem', s. Iagercrantz, "Synopsis des Lappischen" 301; vgl. Bergsland, Studia Septentrionalia V 33, Fussn. 1. Im Dialekt von Gratangen macht sich ein starker lulelappischer Einfluss bemerkbar, und so erinnert die Konstruktion rabie râjien viel mehr an den letztgenamnten Dialekt als an die normale norwegischlp. Konstruktion dâm (Gen.-Akk.) räjest (Lokat. < Elat.) 'scitdem'. Im Lulelappischen werden die Ausdrücke tan (urspr. Ess.) rajēn (urspr. Iness.) 'so weit od. bis dort (z.B. gekommen)' und tat (Partit.) rajeses (Elat.) 'seither, seitdem' (vol. Grundström, a.a.O. 812-813) verwendet; das vorliegende Ta Die râjien ist ein Ergebnis von deren Kontaminierung. Eine solche Konstruktion (Trennungskasus + Ruhekasus) ist hinsichtlich der Urbedeutung ihrer Suffixe unlogisch, im Lichte des für zahlreiche lappische Dialekte charakteristischen Synkretismus aber voll verständlich; das gilt auch für solche in einigen anderen Dialekten auftretende Konnexionen von Ruhekasus + Trennungskasus wie lpI mane muddoost 'in welcher Phase', pyerrin mielast 'bei guter Laume', in denen das Attribut im Essir steht, das Beziehungswort aber in einem aus dem Elativ entwickelten Lokativ.

5.4.2. Ein alleinstehender und sehr merkwürdiger Partitivbeleg findet sich in der kildinlappischen Evangelienübersetzung von Genetz (NyK XV 123): taj $k \bar{u} \chi t$ e $\delta$ pähkmuz ol' poštuv pūkk zakon $i$ prorok 'in diesen zwei Geboten hanget das ganze Gesetz und die Propheten' (Matth. 22, 40). Am Anfang des Satzes findet sich die Kombination dreier Flexionsformen Gen.Pl. + Partit. + Gen.Sg., und die zwei ersten Wörter stehen als Attribut für das letzte, das seinerzeit das Beziehungswort der Postpositionskonstruktion darstellt. Man bekommt den Eindruck, als sei der hinsichtlich des Numerus neutrale Partitiv benötigt worden, die Genitive Pl. und S. als Glieder einer und derselben Wortverbindung zu vereinen.

5.4.3. Aus der oben genannten kildinlappischen Quelle (S. 94) habe ich einen Satz exzerpiert, wo ein Wort im Iık.Pl. 
(urspr. Iness.Pl.) ein partitivisches Zahlwort-Attribut hat:

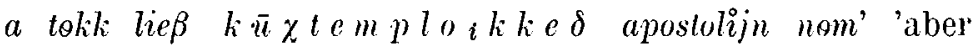
diese sind die Namen von den zwölf Aposteln'. Die Konnexion kū $x$ temploikke $\delta$ apostolijn ist an sich die pluralische Entsprechungr der unter Punkt 5.4.1. behandelten Konstruktion tadie rajien aus dem Dialekt ron Gratangen. Die Bestimmung des im Lok.Sg. stehenden Beziehungswortes kann im Kolalappischen entweder partitivisch oder essivisch sein (z.B. Kld. ozted [Partit.] lainnest 'aus einer Stadt' kolme ${ }^{n}$ [Ess.] pejrest 'in drei Tagen'), und auch die jetzt zu behandelnde Konstruktion Partit. + Lok.Pl. scheint die Konstruktion Ess. + Iıok.Pl. neben sich zu haben: (Akkala)

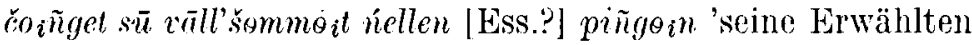
werden alls den vier Himmelsrichtungen gesammelt'(a.a.O. 127).

5.t.4. Bis jetzt sind Fälle behandelt worden, in denen dem Partitivattribut Voll- oder Ilalbkongruenz mit seinem Bezichungswort eignet. Aus dem Inarilappischen ist uns ein von Koskimies anfgezeichneter Partitivattributtypus bekannt, (ler ausserhalh) der Kongruenz steht: kcemali $i$ e ččcid oolas 'Rückenfett von der Stärke der Handkante' (kieččid bzw. leečč $i d=$ Partit. vom Wort kieči bzw. keeči 'Ende'); ohtad (kyehtid, kulmad) suormad oolas 'ein (zwei, drei) Finger dickes Rückenfett' (vgl. oben Punkt 5.1.4.). Diese Konstruktionen wirken in erster Linie elliptisch, denn die Logik würde wohl verlangen, dass man liremakiě̌čid bzw. ohtad suormad assa as oolas 'ein handkanten- bzw. fingerd i c k e s Rückenfett' sagte; d.h. das Wort 'dick' wird nicht genannt, obwohl es sich doch um die Dickheit bzw. Stärke handelt. Falls hier tatsächlich eine Ellipse vorauszusetzen ist, hat sich das Partitivattribut aus einem früheren Adverbiale entwickelt. ()bgleich man nach den Regeln der finnischen Hochsprache z.B. Luutta kyynärää (Partitiv als Adverbiale) korkea (Attr.) huone 'ein sechs Ellen h o he s Zimmer' sagt, lassen sich aus der Volkssprache auch elliptische Konstruktionen nachweisen, die an die obigen inarilappischen Wendungen erimnern. Setälä weist (a.a.O. 53) hin auf die Kalevala-Verse Syltä (Partit.) on housut lahkehesta, puoltatoista 
(Partit.) polven päästä, kahta (Partit.) kaation rajasta 'einen Klafter (b r e i t) sind die Hosen am Hosenbein, anderthalb Klafter am Knie, zwei am Hosenbund'. Natürlich ist hier zu berücksichtigen, dass syltä usw. keine Attribute sind wie die inarilappischen Partitive, sondern vielleicht als Prädikatsnomina aufzufassen sind (urspr. Adverbialbestimmungen: syltä < syltä leveät, usw.). In den finnischen Dialekten begegnet ein seltenes Partitivattribut im Kompositum maatajalka 'kurzbeinig (von bestimmten Tieren gesagt)' (maata = Partit.Sg. von maa 'Erde'). Ich selbst habe auch eine andere dialektale Ausdrucksweise gehört, wo cin partitivisches Substantiv mit seinem kongruierenden Adjektivattribut das Attribut eines zweiten Substantivs ist und somit der Konnexion lpI ohtad suormad oolas entspricht. Diese Konstruktion, pientä (Partit.) kättä (Partit.) mies 'ein Mann von kleinem Wuchs' (wörtl. "von kleiner Hand") hörte ich oft von einem Mann, der - 1884 in der Landgemeinde von Sortavala geboren - guten ladogakarelischen Dialekt sprach. Dennoch ist es m.E. klar, dass die Konstruktionen ohtad suormad oolas und pientä kättä mies trotz ihrer Gleichheit nicht auf derselben Basis entstanden sind. In ersterer scheint der partitivische Teil früher die Bestimmung des $\Lambda$ ttributs (das Adverbiale) gewesen zu sein (vgl. oben), in letzterer aber ging er wahrscheinlich vom Prädikatsnomen zum Attribut über bzw. vom Satztypus mies on pientä kättä (vgl. mies on suurta sukua 'der Mann ist von hoher Geburt'). Man kann infolgedessen auch keinerlei genetischen Zusammenhang zwischen diesen beiden Attributfällen annehmen.

5.5.1. Eine typisch ostlappische Gruppe bildet der Partitiv Singular als Partitivus totius (bzw. Partitivus copiae), der das Attribut des sog. Partialwortes ist.

5.5.2. Als Partialwort steht ein Substantiv: Kld. pińnés $\check{s} a_{i} k k_{e} \delta$ šūrr ćūcco 'man hütete eine grosse Herde Schweine'; pijij kolm mearra jā $v v e \delta$ 'sie vermischte (den Sauerteig) mit drei Scheffel Mehl'; (Šonguj) jeáapaš-vō̃ $l i$

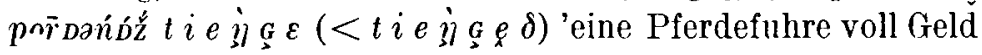

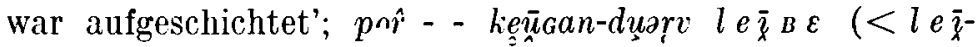
в $\underset{\wedge}{\ell} \delta)$ 'er isst - - einen Backofen voll Brot'; (L. Sza Bó)munn tonne andDă íerc $j \tilde{a} v \boldsymbol{v} \varepsilon$ 'ich gebe dir einen Sack Mehl'. 
5.5.3. Als Partialwort steht ein Pronomen: I manga $r u b$ led 'viele Rubel'; Sk. Pa (Beronka) muadde pa.īo k $e D$ 'einige Höfe, Häuser'; muadoe $\dot{e} k k^{\prime} e_{D}$ 'einige Jahre'.

5.5.4. Als Partialwort steht ein Adverb: Sk. Nrt. jǔennni

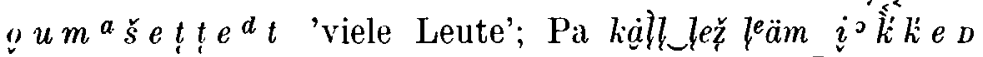
'wieviele Jahre mag es gewesen sein'; temmet $i^{\circ} \bar{k} k$ ' e $p$ 'so viel Jahre'; Kld. lejp-s $\bar{u} j n e \delta$ ienney, a č $\bar{u} p j e$ it te $\delta$ $v a \bar{n} a s$ 'die Ernte ist gross, aber wenige sind der Arbeiter'

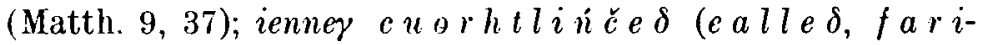

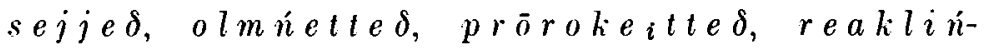
$\check{c} e \delta, s \bar{a} r n j e_{i} t t e \delta$ ) 'viel Besessene (Ware, Pharisäer, Menschen, Propheten, Sünder, Sprecher)'; vānas $i$ e $m n j \dot{e} t-$ te $\delta$ (kuoln $e_{i} t$ te $\left.\delta\right)$ 'wenig Erde (Fischchen)'; monn vie $_{i}$ rt tinest lī lejpe $\delta$ 'wieviel habt ihr Brot?'; monn vie $r$ rt $k \bar{u}_{i} \check{s}_{s} e \delta \quad(v u$ orre $\delta)$ 'wieviele Korb voll (Male)?'; tonn

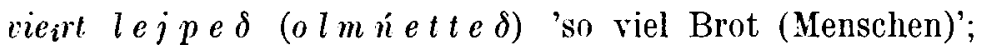
vilgis $\dot{n} u \chi \check{c}$ e $\delta$ kivka ${ }_{i}$ tivt 'weisse Schwäne der Ofen voll';

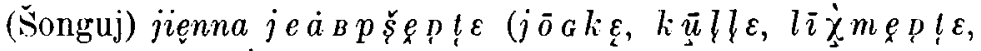
$m \bar{u} r r \varepsilon, t i e \grave{\eta} g \varepsilon, \quad t \underset{u}{u} i j \varepsilon$ ) 'viel Pferde (Flüsse, Fische,

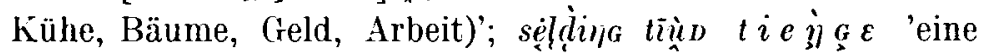
Heringstonne voll Geld'; T (Kert) jEnị vai van $a j i g j$ e $d$. mani 'vergingen viele oder' wenige Jahre'.

5.5.5. Als Partialwort steht ein Zahlwort: I toh finnejii ovdamäädhi-uv jo manga cyeti soll ad 'sie bekamen auch Vorsprung schon viele hundert Klafter'; suu pcrruu loho -lej čiččamlouve jieggad 'die Anzahl seiner Familie -betrug 70 Personen'; čäci-šoalàttah - - oorrij neljilouve $p$ e jvid ja neljilouve $i j j$ ad 'ein heftiger Regen - - regnete

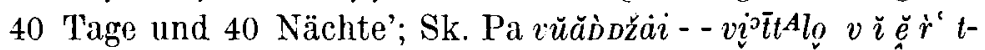

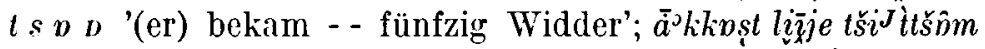

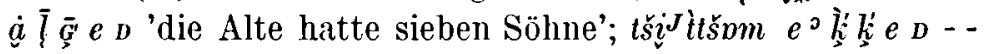

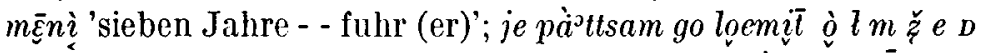

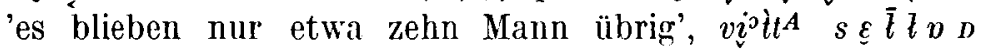

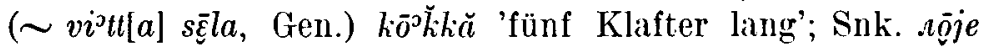

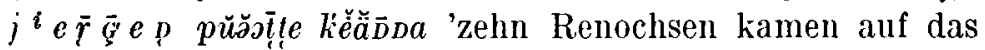
Feld'; Nrt. nook $k^{\prime} k^{\prime}$ o $\bar{u} \dot{m} s^{d} e^{d} t$ kōppì '(er) tötete zehn Männer';

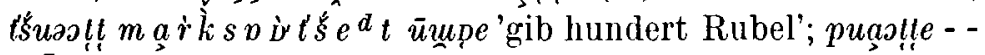

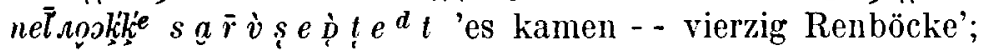

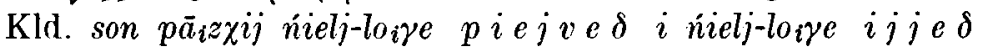




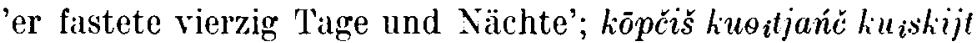
kǐčem tīet $k \bar{u}_{i} \check{s} \breve{s} e \delta$ 'man sammelte sieben Körbe voll übriggebliebene Krümel'; son $r a_{i} l \delta i j$ kiččem lejpe $\delta$ ' nahm sieben Brote'; leaj minest kiččem $v i \imath l j$ e $\delta$ 'es waren unter uns sieben Brüder'; (Šonguj) mon māvsam tuñn̨e loafand $m a \hat{a} \dot{\gamma}$ ' $k$ ' $\mathrm{ich}$ zahle dir tausend Iark'; piellemb

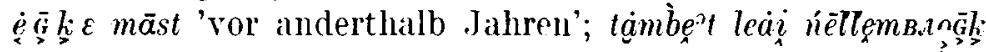

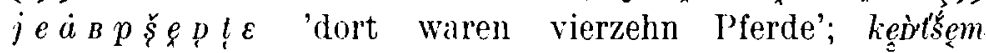

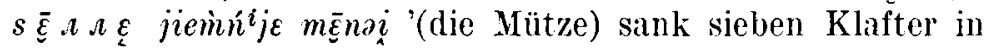

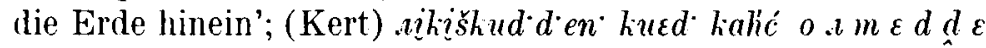
'die Hütte begannen acht Männer zu machen'; nelj.låg $\check{z} u l \chi \varepsilon d d \varepsilon$ pud'den 'die vierzig Räuber kamen'; 'T sist $\check{C} u_{i}$ t tet akca 'bei ihnen (sind) neun Tschuden'; anta räppuš kiččem s a lled 'man grub ein Grab, sieben Klafter

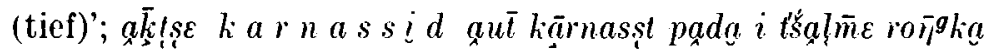
'neun Raben picken einem Raben den Hintern und das Auge aus'; . logke s a $\pi . a^{d}$ kūkade 'zehn Klafter lang'.

5.5.6. Als Partialwort steht die Wortverbindung Zahlwort + Partitiv. In Frage kommen zwei aus den kildinlappischen Texten von Genctz stammende Sätze, die vielleicht auch anders gegliedert werden könnten, als ich es getan habe. Es handelt sich um: $p \bar{o} r j e_{i} t$ t e $\delta$ leaj $a_{i}$ lde ritt toafant olmie $i^{-}$ te $\delta$ 'es gab beinahe fünftausend Personen, die alssen'; $p \bar{o} r^{\prime} j e_{i}$ t te $\delta$ leaj ńielj tōf'nètted olmńetted 'es gab viertausend Personen, die assen'. Meiner Auffassung nach ist also

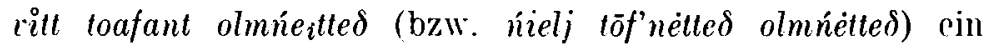
Partialwort, das im Satz als Subjekt steht, und dessen partitivförmiges Attribut pōrjeilted (pōr'jeilled) lautet. Der Satz entspricht also demselben Typ wie z.B. leaj minest kičcem (Subj.) viljed (Partitiv-Attribut) 'es waren unter uns sieben Brüder' oder te $\delta$ olmne $i t t e \delta$ (Partitiv-Attribut) ij ienney (Subj.) lea 'solche Leute gibt es nicht viel'. Die in diesem Punkt behandelte Satzkonstruktion erweckte anch die Aufmerksamkeit von Beronka, a.a.0. 209, und Bergsland, Studia Septentrionalia V 52.

5.5.7. Ungewöhnlich sind zwei in den von L. Szabó aufgezeichneten kildinlappischen 'Texten stehende Numeralkonstruktionen, wo das Beziehungswort des Partitivattributs eine 
rom Zahlwort mit dem Suffix $s$ gebildete Ableitung ist (diese, z.B. vidâs 'fünf Personen zusammen', ist in allen lappischen Dialekten bekannt): ki̋̌ăs parnid 'sieben Kinder sitzen auf der Bank' ("Kolalappische Volksdichtung》 II 10); att kįzaś parned $D \varepsilon$ lafce aln årrăv 'jetzt sitzen dic sieben Kinder auf der Bank', s. a.a.O. 18. In beiden Sätzen bedeutet das Numerale faktisch 'alle sieben'.

- Ich habe ron einem meiner inarilappischen Informanten die hieran erinnemde Konstruktion must laa kääycis (kollektive s-Ableitung) parnaih (Nom. Pl.) 'ich habe (insgesamt) acht Kinder' anfgezeichnet, doch ist es gut möglich, dass kääycis darin gar kein Attribut ist, sondern ein an ungewöhnlicher Stelle plaziertes Prädikatsnomen; m.a.W. lautet der Satz - wenn meine Vermutung zutrifft - in normaler Wortfolge: must la parmaiah kääycis.

5.5.8. Die in Punkt 5.5.2. -5.5.5. behandelten Fälle zeichnen sich dadurch aus, dass der Partitiv in ihnen nicht mehr direkt den Charakter eines 'Trennungskasus hat, obgleich er doch eine Gianzheit bezeichnet, um deren Teil es sich handelt. Archaistisch sind die folgenden Konstruktionen in der kildinlappischen Evangelienübersetzung von Genetz, wo der Partitiv eindentig in der Funktion des Separativ steht: $g_{i} t t$

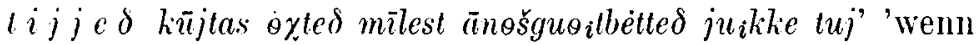
zwei von euch jede Angelegenheit einmütig entscheiden'; kienn leańc sijje d kicmest son liaß'? 'Wes Weib wird sie sein unter den sieben?' (Matth. 22, 28). Diese Partitivformen $\downarrow i j j e \delta$, sijje $\delta$ der Personalpronomina sind insofern merkwürdig, als sie nur ihrer Bedeutung nach pluralisch sind, der Form nach aber singularisch (in norwegischlp. Lautgestalt übertragen *diggjâd, *siggjâd). In den finnischen Entsprechungen der diesebezüglichen Konstruktionen begegnet denn auch schon der Elativ: kakisi teistä; kenen heistä. Auch in der lappischen Konnexion sijjed kičmest 'von ihnen sieben', deren beide Glieder gleichwertige Attribute des Wortes kie 'wer' sind, steht das letztere Glied im Elativ. Das Mordwinische verwendet noch wie das Kildinlappische von den Personalpronomina in diesen Konstruktionen den ursprünglichen Trennungskasus, den Ablativ: kona minderiek 'wer von uns'.

5.5.9. Gemeinlappisch ist der plu $\mathrm{r}$ a $\mathrm{l}$ is che Partitiv 
(> schon im Urlappischen Akk.Pl.) als Attributskasus der Interrogativpronomina: $m \bar{\imath}(g \bar{\imath})$ âl'bmaid 'was für ein Mann' ("welcher von den Männern"). Die genannten Wortverbindungen haben auch im Finnischen mehrere strukturell übereinstimmende Entsprechungen, z.B. mikä olet miehiäsi 'was bist du für ein Mann', eräs uroita 'einer von den Recken'. Ich habe bereits früher hervorgehoben, dass wir in diesen fi. und lp. Konstruktionen einen deutlichen Beweis haben für das Auftreten des Partit.Pl. im Frühurfi. als Trennungskasus, s. CSIFU I 209. In Punkt 6.1.4. werden noch ein paar ostlappische Konstruktionen behandelt, die denselben Typus vertreten wie $m \bar{\imath}(g \bar{\imath}) \hat{a} l$ 'bmaid; in der einen ist das Partialwort eine als Adverbiale gebrauchte Wortverbindung, in der anderen ein Substantiv. Falls die oben unter Punkt 2.2.3.

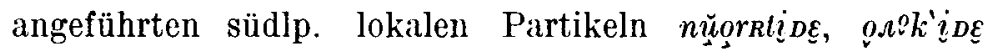
(usw.) tatsächlich pluralisch sind $\left({ }^{*}\right.$ nuortâid, ${ }^{*}$ olgoid $)$, zeigen sie auch, dass der Partitiv in beiden Numeri der Trennungskasus war.

6.1.1. Nun noch einige Ausführungen zu den Abschnitt 5.5. behandelten Fällen, für die aus dem Westlappischen keine einzige Entsprechung vorliegt. Die Verwendung des Partitivs scheint im Kildinlappischen am ausgedehntesten gewesen zu sein. Eine besondere Vorliebe dafür hatte der Gewährsmann von Genetz, mit dessen Hilfe die ersten 22 Kapitel des Matthäus-Evangeliums übersetzt worden sind. Den Heimatort dieses Mannes gibt Genetz nicht an, er sagt lediglich, dass er "ein echter Kildinscher Lappe war» (Wb. S. XVIII). In den anderen kildinlappischen Texten wird mit dem Partitiv sparsamer umgegangen. Im Regionaldialekt von $\Lambda$ kkala dürfte er recht häufig begegnen, da aber wenigstens nach der Schreibweise von Genetz Partitiv und Akk.Pl. hier lautlich weitgehend zusammengefallen sind, was die Benutzung des Materials erschwert, habe ich die Partitivfälle von Akkala übergangen. Allgemein liegt zu wenig Material vor, als dass man ein vollständiges Bild über das Auftreten des Partitivs im Ostlappischen bekommen könnte. Oft werden ...- wie auch aus Beronkas Arbeit erhellt - neben dem Partitiv alternativ andere Kasus verwendet (Gen.-Akk.Sg., Nom.Sg. od. Pl.), ungefähr in derselben Weise wie z.B. im Norwegischlp. Aus 
dieser uneinheitlich anmutenden Vertretung darf man jedoch nicht ohne weiteres schliessen, dass der Partitiv eine finnische Lehnbesonderheit wäre, die die ursprünglichen lappischen Verhältnisse durcheinander gebracht hätte. Es ist nämlich offenbar, dass der Partitiv im Ostlappischen holistisch gesehen eine schwindende, wenn auch immer noch auffallende Erscheinung ist.

6.1.2. Eine deutliche Differenziertheit in der Vertretung der ostlappischen Dialekte besteht insoweit, als in den Punkt 5.5.2. - 5.5.4. behandelten Fällen, wo als Partialwörter Bezeichnungen der Menge stehen ('Gruppe', 'Herde', 'Fuder', 'Sack', 'einige', 'viel', 'wieviel', 'wenig', 'voll', usw.), das Inarilappische zumindest in der Gegenwartssprache nicht den Partitivus totius bzw. copiae einsetzt, sondern stattdessen den Nominativ Sg. oder Pl., z.B. ruudah (Nom.Pl.) mcelgadsă̈ summe 'eine ansehnliche Summe Geld'; stuorra joavklin aal$m u g$ (Nom.Sg.) jä käälguh (Nom.Pl.) 'eine grosse Menge Volk und Frauen'; stuorra joavkku pyecceeh (Nom.Pl.), soohadeh (Nom.Pl.), likkooh (Nom.Pl.) jä vuoččm ulmuuh (Nom.Pl.) 'eine grosse Menge Kranke, Blinde, Hinkende und siechende Menschen'; stuorra joauhuh sehe almaah (Nom.PI.) el käalguh (Nom.Pl.) 'grosse Scharen sowohl Männer als auch Frauen'; cennuu pargo (Nom.Sg.) 'viel Arbeit'; cennuu ulmuuh (Nom. Pl.) 'viel Menschen'; must lii vääni rutta (Nom.Sg.) 'ich habe wenig Geld'; mielkki (Nom.Sg.) lite tieuva 'Milch ein Gefäss voll'; tieuva stuorra kyeleh (Nom.Pl.) '(das Netz war) voll grosser Fische'; koammirtieuva jäauruh (Nom.Pl.) 'eine Handvoll Mehl'. In Verbindung mit den Wörtern kalle 'wieviel' und manga 'manch, viel' tritt der Gen.-Akk.Sg. auf: kalle almaa (päärni)? 'wieviel Männer (Kinder)?'; manga iyve 'viele Jahre' (in einem 1886 von Koskimies aufgezeichneten Text erscheint der Partitiv: manga rubled 'viele Rubel'). Vgl. auch Bergsland, Studia Septentrionalia V 40-41. Meinerseits würde ich es für sehr wahrscheinlich halten, dass der Partitiv in diesen Konnexionen im Inarilappischen durch den Einfluss des Norwegischlappischen geschwunden ist, das von allen Inarilappen im westlichen Teil der Gemeinde neben der Muttersprache und dem Finnischen gesprochen wird.

6.1.3. Hinsichtlich des Russischlappischen fällt auf, dass in 
den Belegren unter Punkt 5.5.2., 5.5.3., 5.5.4. und 5.5.6. das mit dem Partialwort stehende, partitivförmige "Totalwort" (zun Terminus s. Setälä, a.a.0. 50) stets singularisch ist, und nicht nur in der Kategorie der Stoffnamen und Kollektiva,

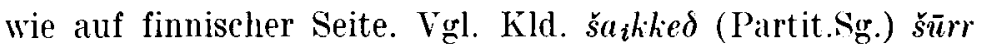
$\check{c} u_{\theta} \varepsilon \sim$ fi. suuri lauma sikoja (Partit.Pl.) 'eine grosse Herde Schweine'; Kld. ienney olmnetted (Partit.Sg.) fi. paljon ihmisiä (Partit.Pl.) 'viele Leute'. Dieser' Lnterschied ist bedeutend, denn er wird zu dem Schluss berechtigen, dass die lp. Partitivkonstruktionen zumindest keine späte osfi. Entlehnung sein können; denn wenn dem so wäre: warum hätte man dann nur den Partit.Sg. zu gebrauchen begonnen, obgleich im Original sicher der Partit. Pl. stand? Giab es doch aluch für den osfi. Partit.Pl. im Lappischen von alters her eine Entsprechung, und sie hat sich lebensfähig erhalten in dem Konstruktionstypus $g \bar{\imath}(m \bar{\imath}) \hat{a} l^{\prime} b$ maid 'was für ein Mann', der' den hier besprochenen Fällen nahesteht und unter P'unkt 5.5.9. behandelt wurde. Ausserdem begegnet der urspr.Partit. Pl. (> Akk.Pl.) in Verbindung mit dem Partialwort aluch im Kildinlappischen, worauf wir bald zu sprechen kommen. Aus der Untersuchung ron Ojajärri geht hervor, dass das kleine südliche Dialektgebiet Russisch-Kareliens wie das Russischlp. in Verbindung mit dem Partialwort nur ein im Partit.Sg. stehendes Totalwort kennt. Z.B. doulko heboista (Partit.Sg.) 'eine Reihe von Pferden', kondieda (Partit.Sg.) äijä 'viele Bären', s. a.a.O. 121-125. Zur Erklärung der Ủbereinstimmung zwischen Südkarelisch und Russischlappisch braucht man keine alten Lehnkontakte zwischen beiden Sprachen anzunehmen, auch wenn sie in der Theorie vielleicht möglich wären. Wörter im Südkarelischen wie 'Gruppe', 'Fuder', 'Bürde', 'viel', 'mehr', 'wieviel', 'soviel', 'voll', 'wenig' usw. verhalten sich als Partialwörter genauso wie die Zahlwörter nach eins, deren Totalwörter überall im Ostseefinnischen im Partitiv Singular stehen. Mit dieser Begründung nahm Ojajärvi an, der südkarel. Typus doukko heboista sei ein Relikt der urfinnischen Vertretung, mit dem verglichen also der finnische Ausdruck joukko herosia (Partit.Pl.) das Ergebnis einer späteren Entwicklung sei. I)iese Vermutung ist jedoch 
ein Fehlgriff, da der Partit.Pl. in Verbindung mit dem Partialwort bereits im Frühurfinnischen als Trennungskasus gebraucht wurde, vgl. oben Punkt 5.5.9.; s. auch Normax Denison "The Partitive in Finnish" 253-256; Verf., CSIFU I 209. Im Südkarelischen ist das Auftreten des Partit.Pl. überhaupt bedeutend seltener als sowohl anderwärts im Ostseefinnischen wie im Lappischen, so dass doukko heboista offenbar auch zu jenen Konstruktionen dieses Dialekts gehört, wo der Singular sekundär an die Stelle des Plurals getreten ist.

6.1.4. Wir können es somit für wahrscheinlich ansehen, dass es bereits im Urfi. solche zweierlei Ausdrücke gab wie (fi.) paljo(n) kalaa (rahaa) 'viel Fisch (Geld)' paljo(n) kaloja (rahoja) 'viele Fische (Geldstücke)'. Dieselbe Doppelheit begegnet auch im Lappischen, so dass wir es hier mit einem gemeinsamen Erbe beider Sprachen zu tun haben werden. Bei meinem Gewährsmann für den kildinlp. Dialekt von Šonguj stellte ich die Tendenz fest, dass er in Verbindung mit dem Wort jienna 'viel' den Partitiv, einen singularischen Kasus benutzte, wenn er die Gattung als nicht näher analysiertes Ganzes meinte, doch stand zumindest das Objekt dann im Plural (also Akk.Pl. < Partit.Pl.), wenn das Totalwort mehrere getrennte Stücke oder Exemplare bezeichnete, die allerdings zur selben Gattung gehörten oder sich gleich sein

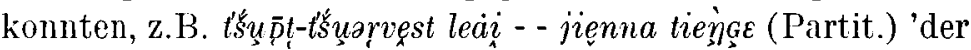

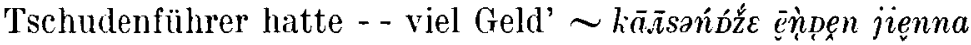
tīgge्रD (Akk.Pl.) 'sie gaben dem Alten viel(e) Geldstücke'. Aus den Texten von Kert habe ich den folgenden Satz exzerpiert, wo in der Funktion des Partialwortes die Wortverbindung liz zlagk' $v^{i}$ arta 'etwa siebzig' steht und der Kasus ihres 'Totalwortes der Akk.Pl. ist: mụne adzsan kižlåglk $v^{i}$ arta (Ill.Sg. vom Wort vier̆d ${ }_{t}^{E}$ 'Quantität, Mass') pudzįit (Akk.Pl.) li 'у моего отца около семидесяти голов оленей' (= 'mein Vater hat etwa 70 Köpfe Rene'; s. a.a.O. 101, 110). Ich vermag nicht zu entscheiden, ob die Pluralität des Totalwortes auch jetzt darauf hinweist, dass die in Frage stehenden Wesen, in diesem Falle die Rentiere, speziell als getrennte Exemplare gesehen werden. Die Wortform der Übersetzung kann allerdings in diese Richtung weisen. 
Auch aus den inarilappischen Texten kann ein Beleg angoführt werden, wo entgegen dem Punkt 6.1.2. genamnten Prinzip das nominativische Partialwort ein im Akk. Pl. stehendes Totalwort hat: - - poodij Baabelist Jerusaleman udda joavkhu juxdálijd (Akk.Pl.) 'aus Babel kam nach Jerusalem eine neue Gruppe Juden', s. Raimmat Historja (Biblische Geschichte), übersetzt von LaURI Itkones, S. 75. Die Wortverbindung udda joavkku jucdalijd (statt jucdaliih) kann durchaus ein versehentlicher Fennismus sein (vgl. fi. uusi jouklo juutalaisia [Partit.Pl.]) oder aber eine Analogieform, beruhend auf Konstruktionen gemeinlappischen Typs wie taih - - addelii vavttaaid stuorra sume (Akk.Sg.) ruudajd (Akk.Pl.) 'diese - - gaben den Wächtern eine grosse Summe Geldstücke', wo das Partialwort (hier summe 'Summe') das Objekt ausmacht und auch seine Bestimmung im Objektskasus steht. Unbedingt wird man den Typus joarkiku jucdilijd aber schon deshalb nicht als sekundär oder unecht zu erklären haben, weil er eine genaue prinzipielle Entsprechung besitzt in der oben genannten Kommexion lpKld, kižlägli viarta pudzįit. Ich verweise auf meine Punkt 6.1.2. geäusserte Vermutung, dass auch das Inarilappische in Verbindung mit Partialwörtern nach Art der anderen ostlappischen Mundarten früher den Partitir verwendet hat. Denselben (iedanken möchte ich anch auf die westlappischen Dialekte ausdehnen; in ihnen wäre der Partit. Sg. oder Pl. nur noch früher zurückgewichen ror dem Nom. $\mathrm{Sg}$. oder Pl.

6.1.5. So wie im Ostfi. und Lp. das 'Totalwort-Attribut der' Partialwörter 'viel', 'wenig' und 'voll' Partitivform aufweist, finden wir in den entsprechenden Konstruktionen des Mordwinischen häufig den Ablativ, so dass der gemeinsame fi.wolg. Ursprung der Erscheinungen kaum bezweifelt werden kann. Z.B. mordw. ja rmaktônza lama 'er hat viel Geld'; kudoś pešliśe lo ma ń $d$ e 'das Haus ist voller Menschen'. Im Nordwinischen steht auch der Ausdruck 'reich an etw:' mit dem Ablativ: supat 'śora t' a li a do 'er ist reich an Söhnen'. (Im Fi. und Lp. Partit. > Elat., z.B. fi. rilias rahasta, lp. rigges rudâst 'reich an Geld'.) Vgl. Júxos Steuer NyK XXII 446, 448; GÉza Fenér Nỵ XLIV 172, 173; Beronka, a.a.O. 208, 209; Ravila, Vir. 1944 S. 124-125. 
6.2.1. Dem Punkt 5.5.5. besprochenen Partitiv bei dem als Partialwort stehenden $\mathrm{Zahlwort}$ ist stets besonderes Interesse entgegengebracht worden. Eine solche Konstruktion ist in allen ostlappischen Dialekten bekannt. In zahlreichen Arbeiten sieht man die Erwähnung, dass im Inarilappischen der Partitiv mit Zahhlwörtern, die grösser sind als 6, verbunden wird. Für das Russischlappische gilt eine unbestimmtere Regel. In den skoltlappischen Texten kann z.B. das Wort für 'fünf' mit dem Partitiv kombiniert werden, und es ist nicht verwunderlich, dass bei der jungen Generation der in Fimuland lebenden Skoltlappen, welche die Hauptsprache des Landes besser als ihre eigene Muttersprache spricht, das Partitivattribut entsprechend der fimnischen Sprache schon für das Wort 'zwei' auftreten kann. Der gleiche Einfluss des Finnischen oder - - in den dortigen Verhältnissen - eher Karelischen zeigt sich auch im Kolalappischen. Nach Konts Beobachtungen wird sowohl im Skolt-als auch im Kolalappisch der Partitiv bereits mit dem Zahlwort für zwei verwendet, hauptsächlich jedoch mit Numeralia über sechs, s. CSIFU I 281. Kert wiederum sagt für das Kolalappische: "Allgemein tritt der Partitiv im Zusammenhang mit Zahlwörtern ab sieben auf", s. Saamskij jazyk 162. In meinen eigenen Aufzeichnungen aus dem Dialekt von Šonguj aus den Jahren 1943-1944 findet sich die damit übereinstimmende Anmerkung, dass sieben das niedrigste Zahlwort ist, das den Partitiv verlangt; ich besinne mich jedoch nicht mehr auf diesbezügliche Nachforschungen meinerseits.

6.2.2. Von Bergsland stammt die verdienstvolle Arbeit "Numeral Constructions in Lapp" (Studia Septentrionalia $V$ 31-68), worin er (S. 39-43) nachweist, dass die in der Literatur verwurzelte Regel, im In arila p p is chen stehe nach Zahlwörtern über sechs i $\mathrm{m} \mathrm{mer}$ der Partitiv, nur eine Seite der komplizierten Numeralkonstruktionen des betreffenden Dialekts zeige. Im folgenden versuche ich kurz, deren Hauptprinzipien zu umreissen.

Vom Standpunkt der komparativen Forschung muss berücksichtigt werden, dass das Inarilappische offenbar schon lange im Stadium des Verfalls lebt. Als ich in den Jahren 1950-1955 lexikalisches und in gewissem Umfang auch gram- 
matisches Material aus diesem Dialekt sammelte und dies mit den Aufzeichungen früherer Forscher verglich, bekam ich den allgemeinen Eindruck, dass die Arbeit, die ich mir vorgenommen hatte, ungefähr hundert Jahre zu spät kam. M.E. gelang es mir jedenfalls, alle diejenigen als Informanten zu erreichen, die ungeachtet der Zwei- oder Dreisprachigkeit, die schon viele Generationen andauerte, noch ausgezeichnet Inarilappisch konnten. In diesen Verhältnissen sind die Texte umso zuverlässiger, je älter die Zeit ist, in die sie zurückgehen. Ich verwende in meinem Überblick hauptsächlich das aus einer Quelle mit vielen Zahlwortkonstruktionen stammende Satzmaterial. Es handelt sich um die bereits oben erwähnte, von meinem Vater Lauri Itkonen (1899-1914 als Pfarrherr in Inari tätig) übersetzte und 1906 erschienene biblische Geschichte (165 S.), abgekürzt RH. Die Veröffentlichung ist sprachlich zuverlässig, da sie in enger Zusammenarbeit mit dem lappischen Lehrer IISAK Masxerua od. PAadar (18301908) ausgearbeitet wurde. Dieser war nicht nur der langjährige Informant des Übersetzers der $\mathrm{RH}$, sondern hatte auch Koskimies und Äimä in derselben Funktion zur Verfügung gestanden, und noch fast fünfzig Jahre nach seinem Tode habe ich gehört, wie man sich an ihn als hervorragenden Sprachbeherrscher des "alten Volkes" erinnert. Einige zusätzliche Belege nahm ich aus der von Koskimies gesammelten und von T. I. ITKonen veröffentlichten Sprachprobensammlung "Inarinlappalaista kansantietoutta" (MSFOu XL, abgekürzt IK) sowie aus meinen eigenen Aufzeichnungen.

6.2.3. Es gibt dreierlei Numeralkonstruktionen im Inarilappischen. Zunächst sind die zu nennen, die in Verbindung mit den Zahlwörtern 1-6 auftreten. Das Zahlwort ist in diesen Konstruktionen stets das Attribut. Die Konstruktionen, deren Attribut ohta 'eins' lautet, unterscheiden sich teilweise von den anderen. Z.B. Nom. ohta kanda 'ein Junge' (Nom. + Nom.), Akk. oouta kaanda (Gen.-Akk. + Gen.-Akk.) $\sim$ Nom.-Akk. kyehti (kutta) kaanda 'zwei (sechs) Jungen' (Nom. + Gen.-Akk.). In den anderen Kasus herrscht zwischen Attribut und Beziehungswort nach altem lappischem Prinzip Voll- oder Halbkongruenz, vgl. oben S. 293. Z.B. Gen. oouta 
(kyeyti, kuuda) kaanda (Gen.-Akk. + Gen.-Akk.), Illat. oouta (kyeyti, kuuda) kaandan (Gen.-Akk. + Illat.), Lokat. ohtan oouta (kyehtin, kuttan) kaandast (Ess. [ Gen.-Akk.] + Lokat.), Komit. ovttäain (kuorttiin, kuudäain) kandaaiin (Komit. + Komit.), Ess. ohtan (kyehtin, kuttan) kandan (Ess. + Ess.), Abess. oouta (kyeyli, kuuda) kandattáa (Gen.Akk. + Abess.).

In Verbindung mit Zahlwörtern über sechs treffen wir zwei verschiedene Systeme an; über die damit verbundenen Bedeutungsunterschiede wird weiter unten die Rede sein. Das eine dieser beiden parallelen Systeme entspricht im Prinzip dem des Ostseefinnischen. Das Beziehungswort der als Subjekt oder Objekt des Satzes stehenden Numeralkonstruktion ist also dann ein Zahlwort in der Grundform (d.h. im Nom. oder Gen.Akk.), gefolgt von einem als Partitivattribut stehenden Totalwort, z.B. tobbeen lijiii kääyci kandad 'dort waren acht Jungen', mun ojnim kääyci kandad 'ich sah acht Jungen'. In den anderen Kasus steht das Zahlwort nicht als Beziehungswort sondern als Attribut, und diese Konstruktionen sehen genau so aus wie die in Verbindung mit den Zahlwörtern $1-6$, z.B. Gen. kääyci kaanda, Illat. kääyci kaandan, Lokat. kähcin kaandast, Komit. kavccīin kandäain, Ess. kähcin kandan, Abess. kääyci kandattäa. Zwischen diesem und dem ostseefinnischen System besteht natürlich der Unterschied, dass auf der letztgenannten Seite zwischen dem Zahlwort-Attribut und seinem Beziehungswort stets Vollkongruenz herrscht (z.B. Allat. kahdeksalle pojalle, Elat. kahdeksasta pojasta), weil die Halbkongruenz hier unbekannt ist.

Anstelle des im obigen Absatz behandelten Systems kann in bestimmten Fällen ein anderes verwendet werden, wo das Zahlwort nach sechs in allen Kasus als Attribut in der Grundform erscheint, während das Beziehungswort in den Kasus des P l u r a ls flektiert wird, z.B. kääyci kaandah '(die) acht Jungen', Gen. kääyci kaandaj, Akk. kääyci kaandajd, Illat. kääyci kandääid, Lokat. kääyci kaandajn, Komit. kääyci kandajgujm, Abess. kääyci kandajttäa. Es erhebt sich vielleicht die Frage, warum beim Zahlwort-Attribut vor dem pluralischen Beziehungswort nicht die geringste Kongruenz. 
auftaucht, obgleich sie in Konnexionen mit Pronominalattribut und häufig auch Adjektivattribut herrscht, wie Nom. ıäih kaandah 'diese Jungen', pyereh kaandah 'gute Jungen', Gen. täaj kaandaj, puorij kaandaj, Akk. täjd kaandajd, puorijd kaandajd, usw. Es kann zumindest die Antwort gegeben werden, dass das Zahlwort-Attribut schon mit seinem pluralischen Beziehungswort kongruieren kann, dass aber eine solche Konstruktion etwas anderes bedeutet als der Typus kääyci kaandah. Kongruenz begegnet nämlich in Verbindung mit solchen Substantiven, die stets oder in bestimmten Zusammenhängen ein Pluraletantum sind, wie hrecjah 'Hochzeit', poostah 'Zinge', püusah 'Hosen', sherreeh 'Schere', lammunh 'Schuhe, ein Paar Schuhe' So wirl z.B. die Konstruktion 'acht Paar Schuhe', folgendermassen flektiert: Nom. liääycih lammuuh, Gen. laaucij lammunj, Akk, laaucijd kammujd. Illat. karcciid kammunid, Lokat. laaucijn kammujn, Komit. kaaucij lammunjgnjm. Abess. kaaucij kammuujttai. Es kann sogar ein solcher Nom.Pl. wie čudeh (< <ude 'Räuber fin Märchen|') vorübergehend als Pluraletantum auftreten in der Bedeutung 'Räuberhorde': tast lej oppeet müut pyeri lukko cet

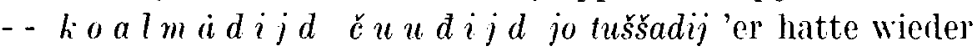
ein so gutes Glück, dass er - - schon die dritte Räubcrhorde vernichtete'. Die Doppelheit im lnarilappischen --. Nom. kääyci kammagid ( kammud), Gen. kääyci kammuи, usw. 'acht Schuhe' - Nom. kääycih kammuuh, Gen. laaucij kammuuj, usw. 'acht Pair Schuhe' - hat eine genaue Entsprechung im Finnischen: Nom. lahdeksan kenhää, Gen. kahdeksan kengän, usw. Nom. kahdeksat kengät, Gen. kahdeksien kenkien, usw. Auch alle anderen lappischen Dialekte verfügen ïber Entsprechungen des Ausdrucks lpl hääycih hammuuh, und diese Pluraliatantum werden auf dieselbe Weise wie im Inarilappischen dekliniert, rgl. Bergsland a.a.O. 35. Vielleicht war das Bestreben, die Flexionstypen liäayci kaandah und kääycih kammuuh voneinander formal getrennt zu halten, ein ausreichender Grund, die Entstehung der Kongruenz im ersteren zu unterbinden.

6.2.4. Wann wird nun im Inarilappischen der Flexionstypus liääyci kandad. Gen. lääyci kaanda, usw. verwendet und wann 
wiederum der Typus kääyci kaandah, Gen. kääyci kaandaj, usw.? Nach Bergsland ist der Unterschied zwischen der letzteren Konstruktion verglichen mit der ersteren "not easy to determine exactly but in most instances the phrase seems to indicate some kind of set consisting of so and so many components (no the same as 'so many sets')", s. a.a.O. 41. Dieser mit guten Beispielen erläuterte Gedanke geht durchaus in die richtige Richtung, und ich kann vielleicht von mir aus -unter Beriicksichtigung des gesamten mir bekannten Materials einige Ergänzungen zu der angeführten Definition hinzufügen. Als Basis für diese Betrachtung zähle ich zunächst eine gamze Reihe ron Belegen auf.

Partitiv (als Attribut des Subjekts:) Kääyci kandad lijiii šiljoost 'acht Jungen waren auf dem Hof'; must laa čičcam kus s ad 'ich habe sieben Kühe'; oho siiz jammii kyeyti väaijuv kyehtičyede ji eggad täan servikoddeest 'im Ianfe einer Woche starben 198 (200 weniger zwei) Personen alıs dieser Gemeinde'; Olla Räädi, mooz kullojiizo ja s a n i d 'der Hohe Rat [der Juden], zu dem 70 Mitglieder gehörten'; tallan ko 70 i h he ed lee nu ham Baabelist 'sogleich wenn 70 Jahre rergangen sind in Babel'; vala lee 40 pej $v$ id 'noch sind 40 'Tage übrig'; -- (als Attribut des Prädikatsnomens:) suu prerruu loho - - lej čiččamlouve j i eggad 'die Anzahl seiner Familie - - war siebzig Köpfe'; -- (als Attribut des Objekts:) mun ojnim kääyci $k$ a n $d$ a $d$ 'ich sah acht Jungen'; Immeel addelij oouce lusis $v \ddot{a} j$ vid poattid Egypt cerennaman 'Gott liess neun schwere Plagen in das Land Ägypten kommen'; sun vaaldij - - luttčyede so a tivavnud 'er nahm sechshundert Kriegswagen'; sun säarnuj 3000 sänilask ud 'er sagte dreitausend Sprichwörter'; - (objektartige Adverbialia; äusserst allgemeine Konstruktion:) Jaakob eelij čiččmnubalah ih he ed Egyptist 'Jakob lebte siebzehn Jahre in Ägypten'; Mooses lej vääriist-- 40 p ej $v i d j a \dot{a} 40$ i jjad 'Moses war 40 Tage und 40 Nächte auf dem Berge'; filistealiih ataštii Israel pánaiajd 20 ih h e ed 'die Philister bedrängten die Kinder Israels 20 Jahre lang'; 46 ih he ed lii tiail tremppal rahtum '46 Jahre lang ist dieser 'Tempel errichtet worden'; - (Partitivus mensurac als Adrerbiale:) ordaliärdin 
- - lej 100 äln $n$ id kukke ja $\breve{0} 0$ ä $l n i d$ kubdur 'der Vorhof (des Tempels) war 100 Ellen lang und 50 Ellen breit'; arkiti koolgaj tohhud kulmčyede ä $l n i d$ kuho, viltlouve älnid kobdo ja kulmlouve $\ddot{a} l n i d$ alo 'die Arche sollte 300 Ellen lang, 50 Ellen breit und 30 Ellen hoch gebaut werden'.

$\sim$ Nom.Pl. (als Subjekt:) Heärrả loppeedij šeštid kaaupug, jos tast ličcii loure $v$ a $n h u r s k \dot{a} h$ 'der Herr versprach die Stadt zu verschonen, wenn es darin zehn Fromme gäbe: ohtnubalah $t \ddot{a} \ddot{a} s n i h$ homerdii suu 'elf Sterne verneigten sich vor ihm'; sii maajeeld paijanii čičcam vastes ja skipa $k u u z a h$ 'nach ihnen standen sieben hässliche und magere Kühe auf'; vuoččin poatih čiččam šien ja eromaš valjeiyveh - -ja tastmana čičćam nelg $i-i y v e h$ 'erst kommen sieben sehr gute Erntejahre - - und danach sieben Hungerjahre'; kyehti kedgitaaulu, mooid laaura louve $p \dot{a} k k u$ $m e h$ lijiii čaallum 'zwei Steintafeln, worauf die zehn Gebote des Gesetzes geschrieben waren'; sij ištii--, čyeti a lma a h. motomáaid 'sie setzten sich nieder - -, hundert Männer in einigen (Gruppen)'; cecennam - - kuččuuj Dekapolin (=10 k a a u$p u g e h$ ) 'das Land wurde - - Dekapolis (= zehn Städte) genannt'; tobbeen lijii ruudah neljilowe s pe e is ige h'dort war Geld 40 Speziesreichstaler'; seämmäa noaidist lijjii čiččam. noajdivuoda jiegah 'derselbe Zauberer hatte sieben Hexerei-Geister'; munnuu čiččam pär $\operatorname{a} \dot{a} h$ lace ajn elimin 'unsere sieben Kinder leben immer noch'; mohheest lappujm tavja kyeht kulm oho, mut lijjii miste kuttlouve $t$ y e l $j i h$ maassat pyehtimnal 'wir blieben oft zwei drei Wochen unterwegs (wörtl. "auf der Fahrt), hatten dann aber etwa sechzig Felle, die wir nach Hause bringen konnten'; - (Prädikatsnomen:) mij lejm čičćam $p \dot{a} r n \dot{a} \dot{a} h$ 'wir waren sieben Kinder'. -Akk.Pl. (als Objekt:) talle vaaldij palvalijjee louve $k$ a $m e^{-}$ lijd 'da nahm der Diener zehn Kamele'; Immeel addelij sunjin mejdej kyehtnubálah o o $\mathrm{lg} i j d$, moj noomah lijiii - 'Gott gab ihm (= Jakob) auch zwölf Söhne, die - - hiessen'; ja täah čiččam skipa kuuzah purrii tajd čiččam mučis ja pyeidis $k u u z z a j d$ 'und diese sieben mageren Kühe frassen die sieben schönen und fetten Kühe'; jos kaaunam Sodomist viltlouve $v$ a $n h u r s k i j d$ 'wenn ich in Sodom fünfzig Fromme 
finde'; sun oažžučij Miikal kälqunis, jos časkaačij 100 fil ist e a lijd 'er bekäme Mikal zur Frau, wenn er hundert Philister schlagen würde'; nuura tääl muu luuz Karmel väarán ubba Israel ja 450 Baal p r of e t $i j d$ 'versammle nun bei mir auf dem Berge Karmel ganz Israel und 450 Propheten Baals'; Jeesus väljee 12 a pos tolijd 'Jesus wählt die zwölf Apostel'; sij - - terdii 12 koorijd lejbipittäajgujm 'sie füllten 12 Körbe mit Brotstücken'; mättäàttaspärnáàh väljejii talle čiččam adalduuvaj ke éčejd (diakonajd) 'die Jünger wälılten dann sieben Wärter der Geschenke (Diakone)'; sij - - maksii sunjin 30 s ilbar u $u d a j d$. - . Juudas - puoutij pajemuuid pappaiaid ja vuorasaiaid maassat tajd kulmlouve silb a $r$ u u $d a j d$ 'sie - - zahlten ihm 30 Silberstücke. - - Judas - - brachte den obersten Priestern und den Alten die dreissig Silberstücke zurück'; munnuj addelij Immeel čiččam $p \dot{a} r$ $n \dot{a} \dot{a} j d$ 'uns gab Gott sieben Kinder'; mun ojnim kulmnubäloh $\imath$ u $u s k i j d$ 'ich sah die dreizehn Leiden' (aus einem Gedicht); lam toalcumin juuhan täjd kyehtnubaloh ucce p a $r$ $n \dot{a} \dot{a} j d$ 'ich bin dabei, diese zwölf kleinen Kinder in den Fluss zu bringen'; sij kuddii ton cooučast kyehtilouve $k u u d d i j d$ ja vitt $k u \circ b \check{z} a j d$ 'sie töteten in dem Herbst 20 Wildrene und fünf Bären'; sun - čconaj nubàloh v yes $i$ a $\dot{a} l d u j d$ 'er band mehr als zehn Renkühe mit Kälbern fest'; ko sun lej purahánnáavuoda annaam 40 pee $i v i j d j \dot{a}$ 40 i $i j a j d$ 'als er 40 Tage und 40 Nächte gefastet hatte'.

Genitiv Sg. kaččalij louce s o o la keäčàn ton pähtiroobdast '(er) rannte zchn Klafter weit von jenem Felsrand'; Mooses lej neljilouve $i$ y $v$ e poaris 'Moses war vierzig Jahre alt'; kääyci pe e ivi keččin - - addeluuj suniin nomma Jeesus 'nach acht Tagen - - wurde ihm der Name Jesus gegeben'; 80 i y ve paaihijn oudemuu joauhu mäccim mana 'ungefähr 80 Jahre nach der Rückkehr der ersten Schar'.

$\sim$ Genitiv Pl. kote nuuračij - - viidad oazi ralje cennuuvuodast čičćam nelgi-i iy $v i$ j verrin '(ein Mann,) der - den fünften T'eil von der Menge des Getreides für die sieben Hungerjahre sammeln würde'; Hoosea, kote ennustij Israelist pajjeel 60 i i y vij ääigi 'Hosea, der in Israel länger als eine Zeit von 60 Jahren prophezeite'; koatucennamsiz mäcceej loho 
lej 50000 j i eg a j paaihijn 'die Zahl der in ihr Heimatland Zurückkehrenden lag bei 50000 Personen'; veärdadas louve ni e $i d a j$ kuatta 'das Gleichnis ron den zehn Jungfrauen'.

Illativ Sg. mun adelim kääyci k a a $n d a n$ 'ich gab (es) acht Jungen'; mun ostim oouce $m \dot{a} \dot{a} r k \dot{a} n$ 'ich kalufte (es) für neun Mark'; rähtamaš kielduuj 14 i ha a 'dor Bau (des Tempels) wurde für 14 Jahre verboten'.

$\sim$ Illativ Pl. Jeesus almosturroo--louce mat $t$ a i $t$ t a spar na $a$ i d 'Jesus erscheint - - zehn .Jüngern'.

Lokativ Sg. liahcin mä ärkis I ij lah tommil 'acht Mark sind nicht genug (d.h. ich begnügr mich nicht mit 8 Mark)'; Junni-Juhinasan laj stuorra iše ton neljinčyettin mä är $k$ is l 'Johannes Johannssohn war mit diesen 400 Mark sehr geholfen'; lohheen suormas ta n, lam nüul hidda, cel jiem oosta kunzzan krejastid 'ich habe alle Hände voll zu tun (wörtl. sich bin so mit meinen zehn Fingern angebundemn), so dass ich nirgendwo hinschawen kann'.

〜 Iokitiv Pl. .Juudas - -, hote lej oht kigehtmubalah mat-

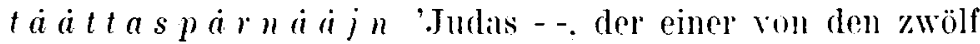
Jüngern walr'.

Komitativ Sy. mun poottim luevion ergi in 'jeh kam mit zehn Renochsen'; mun ostim liaahxijd neljüin čuodiin ma $r h$ ki $i n$ 'ich kaufte Kaffee für 400 Mark'; čččumciain $\check{c} a z$ zi in poossad lialga, kii mun nieida väldid ägu 'mit sieben Wassern soll der sich waschen, der meine Tochter nehmen will' (aus einem Lied).

- Komitativ Pl. Esau poata luu ruasti neljicyede alma ajgujm 'Esill kommit dir entgegen mit 400 Mann'; Jeesus - - iistaj peäudan kyehtnubalah malla $i$ t tas $p$ a $r-$ n i id isliu jm 'Jesus - - setzte sich an den 'Tisch mit seinen zwölf Jüngern'.

6.2.5. Aus dem Beispielmaterial geht meines Erachtens sehr gut hervor, dass der Partitiv und andere singrularische Kasus eigentlich dann gebraucht werden, wemn ausgedrückt wird: $a$. die Anzahl von einer gewissen Gattung angehörenden Lebewesen, Gegenständen und auch Abstrakta, ohne dass eventuell vorhandene gegenseitige Unterschiede berücksichtigt werden, und $b$. rine Quantitä oder Menge, angegehen in Zeit-, Raum- 
und Gewichtsmassen. Eine Wortrerbindung mit partitivischer Bestimmung ist als Objekt eines transitiven Verbums üblich, kommt jedoch in echter Rede kaum als dessen Subjekt vor. Wenigstens habe ich instinktir das Gefühl, dass der Partitiv als Kasus der Benemnung eines aktiven Täters nicht geeignet ist. In Funktionen des Subjekts, des Prädikatsnomens und des (objektartigen) Adrerbiale kann eine Wortverbindung mit Partitiv dann angewendet werden, wenn das Prädikit des Satzes ein intransitives, oft speziell ein Existentialverb ist. (Zu den Existentialverben gehört auch 'sterben' als P'rädikat eines Beispielsatzes auf S. 311; vol. AnRni Pent'In.̈ "Suomen kielioppi" 623, 625.) Die Pluralformen wiederIII zeigen, dass es sich um I n d i vi d u e n handelt, die zu rin und derselben Kategorie gehören, untereinander allerdings recht verschieden sein können. Mit der Pluralität verbindet sich ferner die Vorstellung aktiver Tätigkeit, und ich nehme: aluch an, dass ein unverbildetes Sprachrefühl als subjekt cines transitiven Verbums lediglich den Ausdruckstypus liäüyci kaandah akzeptiert. (Als Sonderfall würde ich den Partitiv als Kasus des Subjekts des transitiven Verbums in folgendem sprichwort sehen: eeči puahta louve alged ajga, mul louce a lged eä pyeyti eeijiz ajga 'der Vater unterhält I= versorgt $]$ zehn Söhne, aber zehn Söhne unterhalten [ = versorgenl ihren Vater nicht'; die Wiederholung der Partitivform kann hier als reines Stilmittel betrachtet werden.) Da mit dem Unterschied zwischen Gattung und Individunm normalerweise auch die Unterscheidung zwischen Unbestimmtem und Bestimmtem verbunden ist, wird durch den Kontrast von singularischen (Partitiv mitgerechnet) und pluralischen Kasus auch die indefinite und definite Spezies ausgedrückt. In einigren Fällen wird der Unterschied zwischen indefiniter und definiter Spezies mit jenem der zufälligen und der endgültigen bzw. einmaligen Anzahl identifiziert: kääyci kandad (zufällige Anzahl) lijjii šiljoost munnuu čiččam parnaiah (endsrültige Anzahl) lece ajn elimin. Der oben erwähnte Unterschied zwischen passiver Existenz und aktiver Tätigkeit kommt m.E. z.B. in den folgenden Sätzen zum Ausdruck: suu perruu loho lej čiččamloure jieggad seämmaia noaidist lijjii 
čiččam noajdivuoda jiegah; man bekommt m.a.W. den Eindruck, dass ein jeder von den sieben Geistern der Hexerei wirksam und effektiv war. Es ist interessant zu sehen, dass man mittels der Verschiedenheit der Numeralkonstruktionen auch zeigen kann, ob es sich jeweils um das $R$ es ultat einer aktiven Tätigkeit handelt oder nicht. Der Schluss des Satzes ko sun lej purahannaixuoda annaam 40 peeivijd ja 40 iijaid könnte zweifellos eingetauscht werden gegen die Form 40 pejvid ja 40 ijjad (vgl. čäci-šsalattah oorvij 40 pejvid $j a \dot{a} 40$ ijjad oben S. 299), doch bedeuten die beiden Sätze nicht genau dasselbe. Der Partitiv teilt lediglich mit, wie lange das Fasten dauerte, während die Konstruktion, wo das Zahlwort als Attribut des pluralischen Akkusativobjekts steht, alle diese mit Fasten zugebrachten Tage und Nächte einzeln als Ergebnis menschlichen Strebens hinstellt. Der Satz lijii miste kuttlouve tyeljih (vgl. S. 312) ist in meiner Quelle übersetzt 'wil' hatten et wa sechzig (= fi. kuutisenkymmentä) Felle', s. IK 103. Ich würde denken, die genaue Übersetzung hiesse 'wir hatten ga n z e sechzig Felle' und es handelte sich un die auch im Norwegischlappischen auftretende und vielleicht auch aus diesem Dialekt entlehnte Konstruktion, von der Konray Nielsex sagt: "Das Substantiv steht hier im Plural und die Absicht ist, die betreffende Anzahl als besonders hoch zu charakterisieren", z.B. vit'tâ-loge boc'cul 'ganze fünfzig Rene', s. "Lærebok i lappisk I» $§ 108$. Gerade um die Mitteilung eines solchen, als besonders gut angesehenen Jagderfolges geht es in der inarilappischen Sprachprobe.

6.2.6. Von den Regelmässigkeiten und Tendenzen, die ich beobachtet habe, treten Ausnahmen auf, von denen die einen - vor allem auf relativ seltene Satzkonstruktionen beschränkt - als ein Zeichen nicht-stabilisierten Sprachgebrauchs gelten dürften, während die anderen anmuten wie provisorische Analogiebildungen oder direkte Lapsus.

In Fällen mit einem Demonstrativpronomen vor Zahlwörtern über sechs lässt sich eine Doppelheit folgender Art feststellen: Nom. täăh čiččam - - kuuzah ( RH 22, vgl. oben S. 312), Akk. tajd čičcam - - kuuzzajd (RH 22, vgl. oben S. 312), läjd kyehtnubäloh ucce pärnäajd (IK 197, vgl. oben S. 313), 
Illat. tooid čyede poccuuid 'jenen hundert Renen' $\sim$ Nom. toh kyehtluvvitt kaanda 'jene 25 Jungen', Gen. toj kyeytluvviida kaanda, Akk. tajd kyehtluvvitt kaanda, Illat. tooid kyeytluvviida kaandan. Von diesen Belegen stammen die ohne Quellenhinweis von meinem Hauptgewährsmann Uula Morotraja (1892-1963), zu seinen Lebzeiten anerkannt als bester Beherrscher des Inarilappischen, erfolgreich auch als Schriftsteller in seiner Muttersprache. Die in Frage stehende Doppelheit zeigt, dass es sich hier um eine Vermischung zweier Systeme handelt. Die Genitivform der Konnexion 'sieben Jungen' beispielsweise kann - wie wir oben gesehen haben - entweder čičam kaanda oder čičcam kaandaj lauten. Man möchte ohne weiteres annehmen, wenn als zusätzliche Bestimmung ein Demonstrativpronomen auftritt, durch das die Wortverbindung in ihrer Gesamtheit die definite Spezies erhält, käme nur der Typus tiaij (toj) čičcam kaandaj in Frage, doch ist also auch taij (toj) čičcam kaanda möglich, beruhend auf der Analogie zum Typus čičćam kaanda. Uula Morottaja selbst schwankte zwischen diesen beiden Konstruktionstypen: Illat. tooid kyeytluvviida kaandan tooid čyede poccuuid.

Ähnliche Mischbildungen treffen wir auch in Konstruktionen an, die mit Hilfe der Zahlwörter 2-6 gebildet sind.

IK 149 findet sich die Akkusativkonstruktion täjd kyehti vieusas a $l$ majd (Akk.Pl.) 'diese zwei starken Männer', die aufzufassen sein dürfte als Kontamination der Konstruktionen kyehti vieusas almaa (Akk.Sg.) und täjd vieusas almajd. U̇blicher dürfte auf jeden Fall die Konstruktion Numerale + Sg. sein: toh kyeht $m \dot{a} t$ t $\dot{a} \dot{a} t$ t a s p äär $n i$ (Gen.-Akk.)

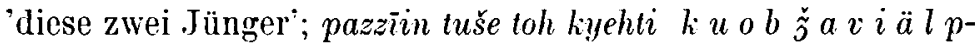
$p \dot{a}$ (Gen.-Akk.) 'es blieben nur jene zwei jungen Bären übrig'; nūut vuobdij tajd kyehti h e ä p pu verkaufte (er) die beiden Pferde'; mottoom täjn kuulma l ä ä š$k i s t$ (Lokat.) acedaj 'einer von diesen drei Faulenzern sagte'.

Befremden kann, dass es in den Texten von $\mathrm{IK}$ recht viele Belege gibt für das Auftreten des Nom.Pl. als Subjektskasus in Verbindung mit einem Zahlwort unter sieben sogar dann, wenn kein Demonstrativpronomen vorangeht: poodiin kyeht 
u $l m u$ u h nieida maajeeld 'zwei Männer folgten dem Mädchen' (S. 58); sun poodij vuojgadvuoda ooudan jä kyeht vieres $u l m u$ $u$ 'sie und die zwei Zeugen kiumen vor das Gericht' (ibid.); tast lijjii kulm a lgeh 'er hatte drei Söhne' (S. 156), kulma a lma a h masa eä kostad cecennaman 'jene drei Männer sind kaum imstande, ihn (= einen Elch aus dem Fluss) ans Land zu ziehen' (S. 119); kulm soatialmaah tallan koččii ceannaman. - - kulm s o a t i a lma a h vala čuošil lijjii 'drei der Soldaten fielen sogleich zu Boden. - - drei der Soldaten standen noch' (S. 148); vitt a lma a h ooudast 'fünî Männer voran' (aus einem Rätsel; bedeutet die Zehen des Fusses) (S. 239); vitt vi i ljah oout rääigi mield kečč ih 'fünf Brüder gucken durch dasselbe Loch' (Rätsel; Antwort: 'die Hand, wenn man sie in den Fäustling steckt'; S. 239); kesl lcee vitt $v$ irge $h$, tast lece hutt ne el $g i h$ 'wer fünf Ämter hat, der hat sechs Hunger' (Sprichwort; S. 224). Besonders aufschlussreich ist Satz Nr. vier, aufgezeichnet bei Uula Morottaja. Er stammt aus einer Sprachprobe, die über die Elchjagd dreier Männer berichtet. Aus dem Sachkontext geht unumstritten hervor, dass liulma alma a h eigentlich $t u o h$ $(\sim t \dot{a} a h)$ kulma almaah 'je ne (bzw. d i es e) drei Männer' bedeutet. Die letztgenannte Konstruktion, wo die Pluralität des Substantivs nach dem Zahlwort eine Folge der Angleichung an den Numerus des Pronominalattributs tuoh (bzw. taih) diarstellt, ist ziemlich ïblich neben den Typus tuoh ( täih) kulma almaa. Man bekommt somit den Eindruck, als sei kulma almaah in der Bedeutung 'jene (bzw. diese) drei Männer' elliptisch entwickelt worden aus der vollständigen Konstruktion tuoh $(\sim t \dot{a} a h)$ kulma almaah. Die meisten anderen unserer Belegsätze lassen eine Ellipsenerklärung deshalb nicht zu, weil sie nicht dasselbe bedeuten wie die Sätze mit dem Demonstrativpronomen taih, woh bzw. toh als zusätzlichem Attribut. Ihnen allen ist gemeinsam, dass sie die definite oder manchnal gencrelle (aber nicht die indefinite) Spezies ausdrücken oder andererseits das, dass die mitgeteilte Anzahl von Wesen endgültig bzw. einmalig ist. In erster Linie hat man an den Einfluss des Typus lääyci kaandah zwecks Hervorhebung der Sonderbedeutung der betreffenden Kon- 
nexionen zu denken: die Doppelheit kulma almaa pottii Lulma almaah pottii kamn in bestimmten Zusammenhängen auch genau dem Unterschied cutsprechen, der zwischen den finnischen Ausdruckstypen lolme miestä tuli 'drei Männer' kamen' kolme miestä tulivat 'die drei Männer kamen' besteht. Nach E. A. SAarima drückt das "pluralische Prädikat, wenn ein Zahlwort Subjekt ist, im Finnischen dasselbe aus wie im Schwedischen der bestimmte Artikel. Hier liegrt also eine Ausdrucksweise der spezies vor", s. "Kielenopas» ${ }^{3} 152 ; \mathrm{vgl}$. Setälï, a.a.o. 14; Oswo IKoLA "Suomen kielen käsikirja" 270. Da es im Iappischen ummüglich wäre, den speziesunterschied im Prädikit zum Ausdruck 7.1 bringen, so blieb allein das Mittel, sich mit dem Wechsel der beiden Numeri im Subjekt zu behelfen.

Zu dem S. 312 erwähnten Ausdruck laauca louve pàlilumeh. des R RI 'die zehn Gebote des Gesetzes' ist zu benerken, dass man im Finnischen häufig sagt Jumalan (bzw. lain) kymmenet käskyt 'die zehn Gebote (Gottes bzw. des Gesetzes)', wobei die Pluralität der Numeralkonstruktion völlig unlogisch wäre, wenn sie nicht die definite Spezies des Wortes für 'Gebot' und die Endgültigkeit der Anzahl der Gebote betonen wollte; gerade dieselbe Absicht verfolgt auch der Nom. Pl. nach dem Zahlwort in dem entsprechenden lappischen Ausdruck. Der Typus laaura louve pakkumeh bzw. Paaveal 13 e p is to la h 'die dreizehn Episteln des Paulus' (RH 159) erschien mitunter greeignet, anch in ähnlichen Konnexionen in Verbindung mit Zahlwörtern untel sieben die definite Spezies auszudrücken: 5 Moosses lirjeh 'die fünf Bücher Mose' (RH 77). Die entgegengesetzten Fïlle scheinen jedoch in der Mehrheit zu sein: 2 Samuel kir je, 2 Kunagazajk $i r j e, 2 A j g i k i r j e$ 'die beidlen Bürher Samuels, die beiden Bücher der Könige, die beiden Bücher der Chronik' (ibid.), Piättir 2 e $p$ is to l a, Johannes 3 episto la 'die beiden Episteln Petri, die drei Episteln Johamnis' (a.a.(). 159).

Noch ein Gesichtspunkt zum Verständnis des Nom.Pl. in Verbindung mit den Zahlwörtern 2-6: in einem Lied (IK 252) steht die Zeile kyehti kuuza, vitta sa a uzah 'zwei Kühe, fünf Schafe', wo dio Pluralität des letzten Wortes befremdet. 
Wenn man jedoch berücksichtigt, dass die vorangehende Zeile kähcilov lijiii poccuuh (Nom.Pl.) 'achtzig waren die Rene (eines Mannes) (d.h. es waren od. er hatte 80 Rene)' lautet, so scheint es nicht unmöglich, dass ritta saauzah eigentlich eine elliptische Variante ist des völlig regelmässigen Ausdruckes vitta lijiii saauzah. Eine solche Ellipse ist in der alltäglichen Rede recht üblich und der elliptische Charakter des Ausdrucks ist - soweit ich mich erinnere - aufgrund des Satzrhythmus und der Satzmelodie mühelos feststellbar.

Das Auftreten des Akk.Pl. mit dem Zahlwort für 'fünf' in dem Satz Daacid - - valjiij jurviist vitt šolis $k$ e ä d $g \dot{a} \dot{a} j d$ 'David - - wählte aus dem Bach fünf glatte Steinchen' ( RH 52) kann nicht als regelmässig angesehen werden. Psychologisch ist diese Numeralkonstruktion jedoch zu verstehen: geschildert wird ein einzigartiger Auftritt, der Kampf I)avids mit dem Riesen Goliath, und durch die Verwendung der Pluralform werden Davids scheinbar geringfügige aber doch effiziente Kampfmittel in zweierlei Hinsicht genau individualisiert: ihre einmalige Anzahl beträgt fünf und durch ihre Glätte unterscheiden sie sich von gewöhnlichen Stcinen.

Dann gibt es entgegengesetzte Unregelmässigkeiten, wo eine mit Zahlwörtern unter sieben stehende Kasusform dann auch bei höheren Numeralia auftritt. Es handelt sich um den Gen.-Akk. als Kasus des Subjekts, Objekts oder Prädikatsnomens statt des Partitivs oder des Nom.Pl. und des Akk.Pl. Einige Belege: kyehtluvvitt $r$ u и $m$ m a $\check{z}$ lijii tast ton majala šiljoost talle '25 Leichen waren da (= während der Seuche) auf dem Hof der Herberge'; tot laj nüut ucce hadde - -, ij lamaž ruinagin, čičćamluvvitt e e y $r i$ 'der Preis (eines aus Rentiermilch gemachten Käses) war so niedrig --, nicht einmal eine Krone, (nur) 75 Öre'; sun - čaalij 51 s a a lm a 'er (= König David) - -schrieb 51 Psalmen' (RH 57); čiččam kirh o lam juo tooham 'sieben Kirchen habe ich schon gebaut' (IK 12); tot äjiih, kot(e) louve ki e l a lej mätám 'der (alte) Mann, der zehn Sprachen gelernt hatte' (a.a.O. 254). In allen Beispielen wäre die Normalform - abhängig rom Aspekt des Sprechers - entweder der Partitiv oder der Plural (rumašid, evrid; salmad, kirkkod, kiellad bzw. ruummažeh; saalmajd, kirhoojd, 
kielajd); meinerseits vermute ich, dass die Verwendung des Gen-Akk.Sg. in erster Linie auf den Einfluss des Norwegischlappischen zurückgeht. -- In diesem Zusammenhang möchte ich daranf hinweisen, dass der Gen.-Akk.Sg. auch bei Zahlwörtern über sechs üblich zu sein scheint in Konnexionen, die angeben, wie viele Male etwas geschieht: moona $j a$ pozadad čiččam k e erdi Jordanist 'gehe hin und wasche dich siebenmal im Jordan' ( $\mathrm{RH}$ 65); njurgodij čiččam ke erd $i$ '(der Zauberer') pfiff siebenmal' (IK 69). Andererseits ist neben letztgenannter die Konstruktion mit dem Akk.Pl. verzeichnet: jees mun - njurgiižzeem čiččam ke erdijd 'wenn ich - siebenmal pfeifen würde'. Da ist dam jeder Pfiff des Zauberers als isolierte, effiziente Aktion gedacht. Die Konstruktion čiččam keerdi pro č. kerdid bzw. ̌́. keerdijd erklärt sich wiederum vielleicht so, dass es sich gar nicht um den Akk.Sg. handelt sondern um eine uralte lappische Konstrulition mit dem

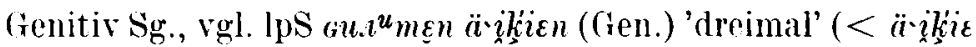
'Mal'); čičcum keerdi ist dann formal völlig regrelmässig.

Als letzter Sonderfall seien die als Objekte benutzten Wörter erwähnt, die sowohl mit einem Zahlwort-Attribut als auch mit einem Possessivsuffix versehen sind. Die Sprache von $\mathrm{RH}$ vertritt in diesen Konstruktionen, die in der täglichen Sprache sehr selten sind, eine solche Verallgemeinerung, dass der Akk.Pl. auch bei den Numeralia $2-6$ auftritt. Weil das Possessivsuffix das Wort im Hinblick auf seine Spezies definit macht, ist es auch natürlich, dass man z.B. sagt - - vuolgatij sun louve o $l g$ i $i$ dis toho 'er schickte zehn von seinen Söhnen dorthin'; - vaaldij sun luuzzas kyehtnubalah $m \dot{a} t t \dot{a} \dot{a} t-$ tas párnaidis 'er nahm zu sich seine zwölf Jünger'. Analog zu solchen Konstruktionen sind die folgenden: Joosef vaaldij kyeht o lgiidis 'Josef nahm seine beiden Söhne'; Iisai addelij tastmara kutt ol $g i$ id $i s$ poattid Samuel ooudan 'Isai liess danach sechs von seinen Söhnen vor Samuel treten'.

6.3.1. Ist nun die exzeptionelle Nuanciertheit der Numeralkonstruktionen im Inarilappischen erst das Ergebnis der Eigenentwicklung dieses Dialekts? Diese Frage lässt sich auch dann äusserst schwer beantworten, wenn aus dem Russischlappischen, das in erster Linie als Vergleich herangezogen 
werden müsste, noch viel neues und zuverlässiges Material gesammelt werden könnte. Ich begnüge mich hier damit, lediglich hinzuweisen auf einige Besonderheiten dieser Dialekte, die an die Verhältnisse im Inarilappischen erinnern.

6.3.2. Wir haben (S. 307) auch für das Russischlappische die Regel als primär erkannt, dass der Partitiv nur in den $\mathrm{Zu}-$ sammenhang mit Zahlwörtern über sechs gehört.

6.3.3. Wie im Inarilappischen begegnen auch im Russischlappischen nach den Zahlwörtern die Pluralformen der Sub-

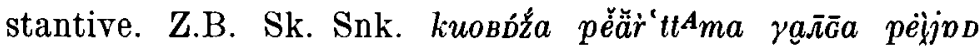

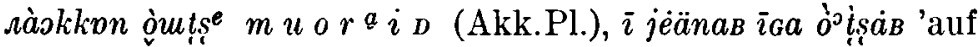
eine Bärenfalle müssen neun Balken als Dach gelegt werden, nicht mehr und nicht weniger'; Kld. vitt lejb' vi $\delta^{\prime}$ toafant o $l m i j$ (Gen.Pl.) vāras 'fünf Brote für fünftausend Leute'; tanna vuolk, $i$ vālt mïldes kiččem $n u_{i} m b i j t v u j \tilde{n} s i j t$ (Akk.Pl.) 'dann geht er und nimmt mit sich sieben andere

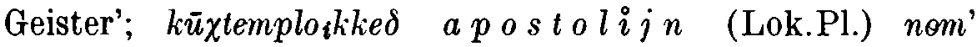
'die Namen von den zwölf Aposteln'; (Akkala) ńellen $p i \tilde{n}-$ go in (Lok.Pl.) 'aus den vier Himmelsrichtungen'; son

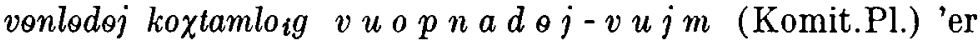
begab sich zur Ruhe mit den zwölf Jüngern'; kasset sānet čudd $j e \dot{r} k i t$ (Akk.Pl.) 'man spannt die hundert Renochsen an die Schlitten an'. Wenigstens in den mir bekannten wenigen Beispielen ist das auf das Zahlwort folgende pluralische Substantiv seiner Spezies nach definit oder die durch das Zahlwort mitgeteilte Anzahl der Gegenstände ist endgültig bzw. einmalig; das Prinzip ist also dasselbe wie im Inarilappischen. Ganz deutlich zeigt sich der Spezies-Unterschied zwischen dem Akk.Pl. und dem singularischen Partitiv darin, dass die im letzten Beispielsatz erwähnten hundert Renochsen, als sie im Text (Szabó, a.a.O. I 50) zum ersten Mal vorkommen und hinsichtlich ihrer Spezies noch indefinit sind, in der Konstruk-

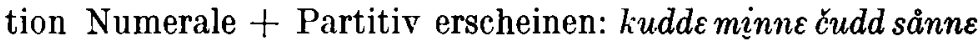
$j a c ̌ u d d j$ je r $\dot{r} k e$ 'lasst mir hundert Schlitten und hundert Renochsen zurück'. Die geringe Anzahl von Belegen beruht zweifellos zum Teil darauf, dass der Gen.-Akk.Sg. und der Nom.Pl. im Russischlappischen lautlich zusammengefallen sind, so dass man z.B. bei der skoltlappischen Konnexion 
$v \hat{\imath}^{\top} \bar{t} t{ }^{A} a \dot{t} \bar{m} m \hat{v}$ 'fünf Männer' nicht wissen kann, ob deren Entsprechung im Inarilappischen vitta almaa oder vitta almaah lautet, die dort beide bekannt sind.

6.3.4. Wie im Inarilappischen ist die Konstruktion Zahlwort + Partitiv in meinem russischlappischen Belegmaterial fast regelmässig entweder ein Objekt, ein objektartiges Adverbiale oder das Subjekt eines intransitiven (Existential-) verbs. Unter den S. 300 angeführten Partitivfällen sind nur zwei Subjekt eines transitiven Verbs. Ich gebe allerdings zu, dass man noch viel mehr Material brauchte, bevor die gegenseitigen Beziehungen von Inari- und Russischlappisch in dieser Hinsicht geklärt werden können.

6.3.5. Da die Konstruktion Zahlwort + Partit.Sg. im Ostseefinnischen allgemein ist und die entsprechende Konstruktion Zahlwort + Ablativ mitunter auch im Mordwinischen begegnet (vgl. Ravila, Vir. 1944 S. 124), besteht die Möglichkeit, dass die Praxis im Ostlp. auf das Frühurfi. zurückgeht und dass einige ihrer Anfangsgründe sogar noch weiter zurückreichen. Ich habe in anderem Zusammenhang (FUF XXXIX 208) die Meinung geäussert, dass sich aus der urlp. Konstruktion Zahlwort + Partit. der schwedischlappische Typus nelie lucke peiiwist (Olaus Graan) '40 Tage', kallie čüutie' nuamielistie (lpU, Halász) 'viele hundert Hasen' entwickelt hat. Auch in vielen anderen Fällen ist der Partitiv im Lappischen zum Elativ geworden, der in schwedischlappischen Numeralkonstruktionen im Zusammenhang mit gewissen höh er en (vgl. den Partitiv des Ostlappischen!) Zahlwörtern erscheint.

6.3.6. Wenn wir dann das System der Numeralkonstruktionen im Ostlappischen, speziell im Inarilappischen, als Ganzes betrachten, fallen ausser der Verwendung des Partitivs auch die Pluralformen der Substantive in Verbindung mit den Zahlwörtern auf. Derartige Konstruktionen sind auch anderwärts im Lappischen nicht ganz unbekannt, denn im Südlappischen und teilweise auch im Umelappischen ist der Nominativ der Numeralkonstruktionen so gebildet, dass von 'zwei' an mit allen Zahlwörtern der Nom.Pl. erschient, z.B. (S) gektz goåtieh 'zwei Hütten', s. z.B. Bergsland, "Røros-lappisk 
grammatikk" 264. Nach Bergsland stehen die anderen Kasus ausser dem Nom.-Akk. in der von ihm untersuchten südlappischen Mundart von Ruros singularisch, z.B. Gen. gektan. goåtien, Iness. gektańa goåtasn, Elat. gektara goåtasta. Zwär sagt er auch, dass wausserhalb des Nom.-Akk. und Komit. ein grosses Schwanken" besteht, doch konnte ich mangels angeführter Belege aus der knappen Darstellung die verschiedenen Erscheinungsformen dieser Schwankung nicht genau erfahren. Dagegen treten die Pluralformen der Substantive "offenbar regelmässig" angeblich dann auf, wenn die Numeralkonstruktion ein pluralisches Demonstrativpronomen als zusätzliches Attribut hat, z.B. dâh gekta goåtieh 'jene zwei Hütten', Gen. dâj gektiej goåtiej. Die Systeme des Süd- und Inarilappischen entsprechen einander also nur teilweise, wenn wir die Schwankungen und Mischformen nicht in Betracht ziehen.

Der südlappische Typus *guok'tè (vit'tâ) goadek 'zwei (fünf) Hütten' hat stellenweise im Ume- und Pitelappischen Entsprechungen (neben dem Typus guok'tě goade), sogar auch in der Südgruppe des Norwegischlappischen, s. Bergsland, Studia Septentrionalia V 38-39. Ausserhalb des Südlappischen ist jedoch die Konstruktion rom Tỵ guok'tě (vit'tâ) goade viel weiter verbreitet, wo das Substantiv nach dem Zahlwort den blossen Stamm aufweist und z.B. bei den dem Stufenwechsel unterliegenden Zweisilblern ausdrücklich schwachstufig ist (wie goade < goatte 'Hütte'). Nach Bergslands Auffassung ist diese schwachstufige Stammform goade etymologisch identisch mit der Form in der südlp. Konstruktion *guok'tě yoadek, d.h. der Nom.Pl., mit einem Schwund des auslautenden $k$. Das Südlappische ist ja auch sehr konselvativ hinsichtlich der Konsonanten im Wortauslaut, während anderwärts z.B. gerade der Vertreter des urlp. Auslaut- $k$ in den meisten Formoruppen geschwunden ist. Das gilt jedoch mit Ausnahme des Russischlappischen nicht für den Nom.Pl. (z.B. L kấtehh, N goadek, I koadeh, koadih 'Hütten, Lappenzelte'), welchen Umstand Bergsland so erklärt, diass das $k$ oder dessen Vertreter aus den einsilbigen Pronomina, wo es sich allgemein besser erhalten hat, wieder ins Paradigma der Substantive eingeführt worden sei, s. a.a.0. 62. 
6.3.7. Als wichtigen Vergleichspunkt zieht Bergsland noch das Mordwinische heran, wo nach normalem Gebrauch bei Zahlwörtern ab 'zwei' das Substantiv im Nominativ pluralisch, in anderen Kasus aber singularisch ist, z.B. karto kudot 'zwei Häuser', Gen. kavto kudoń, s. a.a.O. 63. Die U̇bereinstimmung zwischen den Verhältnissen im Südlappischen und Mordwinischen ist tatsächlich gross. Es darf jedoch nicht übersehen werden, dass in der unbestimmten Deklination des Mordw., wonach die mit einem Zahlwort-Attribut versehenen Substantive flektiert werden, kein anderer pluralischer Kasus existiert als der Nominativ, so dass alle anderen Kasus, wie der Genitiv, zwangsmässig singularisch sind. Im Lappischen wiederum verfügen die Substantive über eine vollständige Pluralflexion. Unter diesen Umständen wäre es recht merkwürdig, wenn nicht nur das mordw. System (kavto kudot kavto kudoń usw.) sondern auch das südlappische (gelita goåtieh $\sim$ geltan goåtien usw.) jeweils die Verhältnisse aus der fi.-wolg. Zeit unverändert beibehalten hätten, die hinsichtlich des Lappischen - vor dem Hintergrund des entwickelten Deklinationssystems der Sprache betrachtet -.- nunmehr direkt unlogisch wirken. Ferner ist zu berücksichtigen, dass sowohl im Süd- wie im Umelappischen Dialekte existieren, in denen der Plural auch in anderen Kasus als dem Nominativ erscheinen kinn, z.B. Gen.Pl. S (Hatfjelldalen) manne aččeb supcstit guökte sami-b a $r n i$ bire 'ich will von zwei Lappenburschen erzählen'; akten aigin guöhte samie aččin mennet guökte varie $j$ a $w r$ guaiku 'einmal sollten zwei Lappen nach zwei Gebirgsseen gehen'; U (Malå) čihča vi e ll ja $i$ carra 'das Blut von sieben Brüdern'; Akk.Pl. U (Malå) uhčes loddačen čihča č eukit 'sieben Junge eines Vögelchens'; Ill.Pl. S (Hatfjelldalen) so dihte nieiden ahčie jiahta guölte samien $b \ddot{a} r n i d e$ 'dal sagt der Vater des Mädchens zu zwei Lappenburschen' (vgl. Bergsland, a.a.O. 39, wo auf diese Fälle verwiesen wird).

6.3.8. Die Vielgestaltigkeit der Konstruktionen am Südrand des lappischen Sprachraums erinnert stark an die Vertretung im Ostlappischen. So kann man gut die Frage stellen, ob nicht in dem System, das nach der Meinung von Bergsland z.B. im 
Dialekt von Røros normal ist, Systeme verschmolzen sind, die z.B. im Inarilappischen noch isolierte, logische Konstruktionen ausmachen (z.B. Nom. kyehti kaanda 'zwei Jungen', Gen. kyeyti kaanda usw. kääyci kaandah '[die] acht Jungen', Gen. kääyci kaandaj usw.).

Ich halte Bergslands Auffassung von der genetischen Zusammenhörigkeit der südlp. und mordw. Zahlwort + Nom. Pl.-Konstruktionen durchaus für möglich. In den lappischen Numeralkonstruktionen selbst gibt es - - soweit ich sehe keinen sachlichen Grund, der den entsprechenden ostlappischen Typus (I kääyci kaandah usw.) aus diesem Zusammenhang ausschliessen lassen würde, was Bergsland jedoch tun möchte, s. a.a.O. 63. Dass die Konstruktion kääyci kaandah als spät entstanden erklärt wird, setzt lediglich seine eigene Theorie voraus, wonach im Typ kyehti kaanda der ursprüngliche Nom.Pl. mit geschwundenem $k$ erhalten wäre. Gerade aus diesem Grunde lohnt es sich, auch weiterhin die Erklärungsmöglichkeit ernsthaft in Erwägung zu ziehen, dass das Beziehungswort der Numeralkonstruktion guok'tě (vit'tâ) goade auch ursprünglich das wäre, als was es im Lichte der vergleichenden Dialektforschung deskriptiv zu definieren ist, nämlich der blosse abstrahierte (in diesem Worttypus schwachstufige, in einigen anderen Worttypen wiederum starkstufige) Stamm. Ich übergehe hier die Frage, wie man zu einer solchen, der grossen Verbreitung des Typs nach zu schliessen schon frühzeitig eingetretenen Abstraktion gekommen wäre.

Ohne zu zögern lehne ich die auch geäusserte (vgl. Beronki, a.a.O. 104) Erklärung ab, dass die südlappisch-umelappische Konstruktion Zahlwort + Nom.Pl. auf die frühere Konstruktion Zahlwort + Partit.Sg. zurückgeht. Nach dieser Hypothese hätte im Lappischen, wie im Finnischen, der Nominativ aller anderen Kardinalzahlen als 'eins' mit dem Partit.Sg. des Substantivs gestanden. Wenn dem aber so wäre, warum hätte sich dann im Ostlappischen der Partitiv lediglich bei Zahlwörtern über sechs erhalten, wäre aber bei niedrigeren Numeralia gegen die Form des Gen.-Akk. bzw. (möglicherweise im Russischlappischen) Nom.Pl. eingetauscht worden? 
6.3.9. Obgleich die Konstruktion Zahlwort + Nom.Pl. im Lapp. und Mordw. also gemeinsamen Ursprungs sein kann, darf meines Erachtens hieraus nicht direkt geschlossen werden, dass eine solche Konstruktion sagen wir in der fi.-wolg. Ursprache in Verbindung mit anderen Zahlwörtern als 'eins' a us chli esslich war. Man dürfte allgemein zugeben, dass schon in früher Zeit z.B. in der Form des Objekts ein Wechsel hat auftreten können nach solchen Gesichtspunkten wie Totalität oder Partialität des Objekts, definite oder indefinite Spezies, Zugehörigkeit zur belebten oder unbelebten Klasse, Aspekt bzw. Grundbedeutung des Prädikatsverbs. Es erhebt sich die Frage, ob man nicht auch in der Form des mit einem Zahlwort stehenden Substantivs bereits in zurückliegenden Entwicklungsplıasen der Gegenwartssprachen Ausdrucksmittel hat suchen können für eine derartige begriffliche Mannigfaltigkeit, deren Zwecken die diesbezüglichen Konstruktionen in allen lappischen Dialekten dienen; d.h. ob nicht vielleicht die vom Standpunkt die fiu. Sprachen stets als ursprünglich erklärte Konstruktion Zahlwort $+\mathrm{Sg}$. als Indikator der Menge für bestimmte Bedeutungsnuancen auch die Konstruktion Zahlwort + Pl. neben sich hatte. D. R. FokosFucrs hat aus den ural-altaischen Sprachen eine derartige Doppelheit ziemlich reichlich belegt, s. ALH X 440-451. Die pluralischen Formen, die der Verfasser als unerschütterlicher Anhänger der genannten herkömmlichen Auffassung (vgl. auch FUF XXIV 298) als isolierte sekundäre Entwicklungen erklärt, haben allgemein eine gleichgerichtete Funktion wie die lappischen Numeralkonstruktionen entsprechenden Typs. Gerade dieser Umstand ist aufschlussreich und spricht vielleicht für den autochthonen und auch alten Charakter der lappischen Konstruktionen Zahlwort + Pl, denn wenn man diese z.B. auf den Einfluss skandinavischer Sprachen zurückführen wollte, so wäre es etwas eigenartig, dass sie insbesondere ostlappischerseits mit den ursprünglichen Konstruktionen Zahlwort + Sg. zu einer so zweckdienlich anmutenden Arbeitsteilung gelangt wären.

6.3.10. Vielleicht habe ich jetzt die Hintergrunderscheiluungen meines eigentlichen Themas, des mit dem Numerale 
verwendeten Partitivs, zu ausführlich herangezogen, nicht um die darin liegenden Probleme zu klären, sondern in der Hoffnung, dass diese Fragen in der Zukunft stärkere Berücksichtigung fänden. Ich konzentriere mich nun auf die Hauptsache und stelle fest, dass nicht nur die Verwendung des Partitivs sondern auch die Numeralkonstruktionen als Ganzes gesehen im Ostlappischen beachtlich abweichen vom ostseefinnischen System. Auch Bergsland gibt zu, dass "the Eastern Lalpp distinction, in basic construction, between 'two' to 'six' on the one hand and higher numerals on the other could possibly be an archaism", s. Studia Septentrionalia V $\mathbf{4 6 - 4 7 .}$ Und doch sagt er andererseits, dass das Nichtauftreten des Partitivs in den zusammengesetzten Numeralia des Lappischen "does not necessarily prevent the Eastern Lapp numeral constructions with partitive from being an old type but the evidence for it being old is very slight indeed", s. a.a.0. 53. An einer anderen Stelle wiederum erläutert der Autor einen besonders wichtigen Tatbestand folgendermassen: "But even if -... or rather particularly if - the Eastern Lapp partitive constructions should turn out by closer examination to be archaic rather than due to Finnish influence there can be 110 question of the lower numerals having been constructed with the partitive in Primitive Lapp: how could the partitive, a perfectly normal case according to the assumption we would have to make, be wiped out just in constructions with lower numerals?", s. a.a.O. 56 .

Ich möchte Bergslands ganz richtige Schlussfolgerung folgendermassen weiterführen: wenn die ostlappischen Partitivkonstruktionen aus dem Finnischen entlehnt wären, wie ist es dann möglich, dass sie nur in Verbindung mit Zahlwörtern ïber sechs Eingang fanden? Eine solche grundsätzliche Grenze, wie sie im Ostlappischen zwischen den Zahlen 6 und 7 verläuft, begegnet ja auf ostseefinnischer Seite überhaupt nicht. Da die vergleichende Dialektforschung des Lappischen ausserdem zeigt, dass bereits die Urlappen über ein im morlernen Sinn voll entwickeltes Numeralsystem mit gemeinsamen einfachen und zusammengesetzten Zahlwörtern im gesamten 
Sprachraum verfügten ${ }^{1}$ - nur für solche Begriffe wie 'tausend' und 'Million' mussten später fremde Namen entlehnt werden -, muss man unbedingt zu dem Ergebnis kommen, dass die ostlappischen Partitivkonstruktionen nicht das Resultat ron Lehnberührungen sein können, sondern dass sich in den Regeln ihrer Verwendung eine aus früheren, vielleicht auch sehr alten Zeiten stammende Besonderheit erhalten hat, die im Ostseefinnischen geschwunden ist. Mehr zu dieser Frage Abschnitt 9.

7.1. Zur Ergänzung seien noch zwei Verwendungsweisen des Partitivs angeführt, die sich auf einen einzigen Dialekt beschränken dürften, auf das Inarilappische.

7.2. Von syntaktischem Standpunkt gewiss als $\mathrm{Adver-}$ b i a le (nicht als Prädikatsnomen) zu deuten ist doch wohl die Partitivform tade vom Wort tot 'er, sie, es' mit der Anhängepartikel gin 'auch nicht, nicht einmal', die mit wechselnden Bedeutungen als Bestimmung der negierten Formen des Verbums lede 'sein' auftritt, z.B. tot ij leem tadegin, ko eergi laj vuaijam 'er war nicht erfreut, dass (ein anderer) mit seinem Renochsen gefahren war'; aber: Vuolli-Saammal ij lem tadegin, rajkik täalu puolij 'V.-S. liess sich nicht stören, obwohl das Haus brannte'.

Man hat den Eindruck, als bedeutete die Konstruktion Neg. Form + tadegin eigentlich 'gar nicht, keineswegs', doch können solche elliptischen Ausdrücke wie »er war gar nicht" situativ als Ersatz für semantisch genau entgegengesetzto

${ }^{1}$ Lnbegründet ist Bergslands Vermutung über das Zahlwort čuotte (a.a.O. 53), wonach die Urlappen hardly knew the Iranian 'hundred' otherwise than as a word for some very high number*. In allen fiu. Sprachen bedeutet dieses Wort '100', was zweifellos auch schon für die fiu. Grundsprache gilt. Lediglich im südlappischen Dialekt, wo auch einige andere Bezeichnungen höherer Numeralia auf einer eigenartigen Sonderentwicklung beruhen, ist eine spāte Bedeutungsentwicklung 'hundert' > 'tausend' eingetreten. Ob hier wohl als Zwischenstufe der Versuch verborgen liegt, das Bezeichnungsproblem des letztgenannten hohen Numerale durch dasselbe amüsante Reduplikationsverfahren zu lösen, das Olaus Stephani Graan in seinen Übersetzungen verwendet, wenn er als Benennung für 'tausend' guete guete bzw. giåte giåte hat, also eigentlich whundert hundert»? 
Sätze verwendet werden, wie "er war keineswegs froh", "er war keineswegs traurig». Über die Herkunft der lappischen Redensart kann ich nichts sagen. Finnischen Ursprungs dürfte sie kaum sein; mir sind zumindest keine Erwähnungen von Konstruktionen wie *ei (en, et) ollut sitäkään bekannt, die den im Inarilappischen auftretenden entsprächen.

7.3. Als P r äd i k a t s n o m e n erscheint made, der Partitiv von mii 'was', in solchen Sätzen wie puoh rahtii kiedaj, mii la ̌̆ lam made 'alles machten sie mit der Hand, was es auch sein mochte'; Sulgušjääyrist laa puoh šiljo veäštust, mii la ̌̌ made! 'im Haus Sulkusjärvi ist alles auf dem Hof durcheinander, hier dies, hier das!' Die Konnexion mii made wirkt finnisch beeinflusst, vgl. fi. miliä mitäkin 'dies und das; der eine (lies, der andere das'.

8.1. Mein Ausgangspunkt bei der Untersuchung der Partitivverwendung im Ostlappischen war die Auffassung, dass der Partitiv in diesem Raum sprachhistorisch gesehen keine sichtbarere Stellung einnimmt als im Schwedischlappischen. Ich gebe im folgenden eine kurze Zusammenfassung meiner Ergebnisse, wobei ich die seltensten und als solche vielleicht mehr oder minder provisorischen Partitivbelege in einzelnen Redewendungen u.durl. übergehe.

Ich habe die Partitivfälle aufgrund ihrer syntaktischen Funktion gruppiert.

Als Adverbiale verwendete partitivförmige Partikeln (Abschnitt 2) begeguen in gewissem Umfang überall, doch ist diese Gruppe im Schwedischlappischen deutlich am grössten und lebensfähigsten.

Der als Adverbiale benutzte Partitivus comparationis (Abschnitt 3) ist ebenfalls überall bekannt, im Westlappischen jedoch nur rudimentär. Das Ostlappische hat für diese Konstruktion eine ausgedelnnte Verwendung.

Auch der Partitiv als Beziehungswort der Post- und Präpositionen (Abschnitt 4) ist im Westlappischen ungefähr im gleichen Ausmass zurückgegangen wie in der vorangehenden Gruppe, doch liefert das Lulelappische offenbare Beweise dafür, dass sich der Kasus auch hier früher einer ausgedehnteren Verwendung erfreute. Im Ostlappischen ist die Gruppe lebensfähig. 
Ausserordentlich vielförmig tritt der Partitiv als Attribut auf (Abschnitt 5).

Für ein Partitivattribut in Voll- oder Halbkongruenz mit seinem Beziehungswort (Abschnitt 5.2.) liegen ziemlich viel Belege sowohl aus dem Russischlappischen als auch aus dem Schwedischlappischen vor. Die Vollkongruenz (Partit. + Partit.) war früher in gewissen Fällen im Bereich der südlappisch-umelappischen Dialekte systematisch, während die Vorkommen im Ostlappischen rudimentären Charakter haben. Die Halbkongruenz (Partit. + Elat.) ist im Schwedischlappischen weiterhin das konsequente System, was wohl ron keinem der russischlappischen Dialekte gesagt werden kamn. In dieser Untergruppe, die im Inarilappischen fast völlig fehlt, ist das Schwedischlappische am stärksten vertreten.

Rein ostlappisch und für diese Mundarten sehr typisch ist die Untergruppe: Partitivus totius (bzw. copiae) als Attribut (Abschnitt 5.5.). Durch die einseitige Überbewertung dieser Fälle entstand gerade die Auffassung, der Partitiv sei ein speziell ostlappischer Kasus.

Eine sprachgeschichtlich sehr wichtige Gruppe bildet der Partitiv als Objektskasus, den ich FUF XXXIX behandelt habe. Belege dafür liegen uns lediglich aus dem Schwedischlappischen vor, wo er noch im 18.Jh. im südlappisch-umelappischen Dialektgebiet lebendig war.

Die Belege für den ursprünglichen Partit.Pl. (>lp. Akk. Pl.), die ich im Zusammenhang mit den einzelnen Abschnitten vergleichsweise herangezogen habe, scheinen durchweg meine Auffassung von der Existenz sowohl eines singularischen als aluch pluralischen Partitivs - teilweise noch in seiner urspr. Funktion als Trennungskasus -... im Frühurfi. zu unterstützen, von wo aus beide ins Lappische gelangten.

Bei der Erforschung des lappischen Partitivs war die Problemstellung allem Anschein nach einseitig, da das Hauptaugenmerk dem ziemlich zahlreichen Auftreten dieses Kasus im Ostlappischen galt. Man hätte vor allem versuchen müssen zu klären, wodurch der starke Rückgang des Partitivs im lappischen Hauptdialekt, dem Norwegischlappischen, verursacht wurde. Diese Frage lohnte sicher eine Untersuchung, doch möchte ich zumindest hier nicht darauf eingehen. 
8.2. Ich habe mit meinem Aufsatz in erster Linie das Bild präzisieren wollen, das in zwei beachtlichen Untersuchungen ïber die Geschichte des Partitivs gegeben worden ist, in Bernnkas "Lappischen Kasusstudien" und in Bergslands "Numeral Constructions in Lapp". Ihre Kenntnis ist umumgänglich für jeden, der die Entwicklungsphasen des Partitivs klären will. Von den Ansichten meiner Vorgänger habe ich einen ziemlichen Teil als solchen akzeptiert, doch konnte ich mich keinem der beiden Standpunkte vorbehaltlos anschliessen. Wenn Bergsland auch in seiner mustergültigen Kenntnis und sicheren Beherrschung eines umfangreichen und heterogenen Materials über Beronkas Errungenschaften hiniusreicht, dürfte ich hinsichtlich meiner Grundanschauungen doch dem letztgenannten näherstehen. Neben diesen beiden Arbeiten möchte ich Nielsens grundlegende Studie "Partitiv i Fimmark-lappisk" (Festskrift Qvigstad 1928 S. 168--178) erwähnen, deren Hauptresultat, dass der Partitiv im Norwerischlappischen beachtlich zurückgegangen ist, noch immer seine Gültigkeit hat. Andere notwendige Quellen für den Erforscher des lappischen Partitivs sind ferner die oben besprochenen Veröffentlichungen von Wiklund, Ravili, I)enison, Kont und Bartens.

9.1. Wie ich unter Punkt 6.3.10. sagte, hat man hinsichtlich der vielleicht anffallendsten Einzelheit der Anwendung des Partitivs im Ostlappischen, der Konstruktion Kardinalzahlwort + Partitiv nämlich, die Erörterung del Frage versäunnt, warum der Partitiv erst bei Numeralia über sechs rebräuchlich wird. Dies muss natürlich schon aus dem (irund gefragt werden, weil sich die betreffende lappische Partitivkonstruktion als eindeutig autochthon erweist, wenn als Virgleich die ganz andere Instribution des Partitivs in den finnischen Numeralkonstruktionen herangezogen wird.

Die Benennungen der Zahlwörter $\mathbf{1}-\mathbf{6}$ haben im (Istsepfinnischen und Lappischen nichts Merkwürdiges, doch fällt die Schwachstufigkeit der (4rundform der Wörter 8 - 10 in zahlreichen lp. Mundarten auf, z.B. Ip X gacce '8', orce '9', loge '10' (aber meist gak'ce-loge '80', ok'ce-loge '90' mit starker' Stufe in der ersten Komponente). Zumindest teilweise handelt 
es sich hier in deskriptiver Sicht um Akkusative, was sicher z.B. für $1 \mathrm{pL}$ låkèv ' 10 ' gilt, dessen $v<m$. BJöRN Collinder vermutet, auch die auf $n$ endenden Formen im Finnischen, seitsemän '7', kahdeksan ' 8 ', yhdeksän '9', kymmenen '10', (tuhannen '1000') »dürften mithin am einfachsten durch die Annahme erklärt werden können, dass in gemeinfinnischer Zeit -- oder schon früher - eine gewisse Konfusion zwischen nsg und asg stattgefunden haben, s. Festskrift Qvigstad 373; vgl. auch Vir. 1953 S. 92-97. Andererseits hat Collinder darauf hingewiesen, dass die akkusativartigen Formen verursacht sein können durch eine Verallgemeinerung des zum Stamm des Wortes für 'sieben' gehörenden $m(\operatorname{lpN}$ čiežâ, L kietjav < *čiežâm, vgl. fi. seitsen < seitsem-) in den anderen benachbarten Zahlwörtern, s. Festskrift Qvigstad 368-373. Diesem Gedanken hat sich auch Bergsland angeschlossen, obwohl er andererseits für möglich gehalten hat, dass die lappischen Wörter für $7-9$ von den entsprechenden, auf $n$ ausgehenden Numeralia des Finnischen beeinflusst, wenn nicht direkt von dort entlehnt worden sind (wie auch von einigen anderen Forschern vermutet), s. Studia Septentrionalia V 48--49. Ich selbst glaube auch, dass die scheinbaren Akkusative rom Typ laker auf der Analogie zum Typus hietjav $\left(<{ }^{*}\right.$ čie żâm) beruhen, dass aber die Wörter gacce und ovce die Fortsetzungen der frühurfi., auf $n$ endenden Formen (vgl. unten) sein können, die -- lautlich den zweisilbigen Stämmen angeglichen -- auch dem Stufenwechsel unterzogen werden konnten. Sie als osfi. Lehnwörter auszulegen ist meines Erachtens nicht nur unbegründet. sondern auch unmörrlich.

Bergsland bringt die bekannte Tatsache zur Sprache, dass 1 urr die Zahlwörter 1--6 allen fiu. Sprachen gemein sind. Ausserdem zeigt sich in den zusammengesetzten Numeralia einiger dieser Sprachen eine Konstruktionsänderung beim Übertrang von 60 zu 70 : syrj. ko-min '30' . . kvaiti-min '60'; wor. näl-man '40' . . q qōt-pan '60' (der Schlussteil dieser Termini syrj. $\min$, wog. man, |>] pan ist mit dem fi. Wort moni 'inanche[r], viele[r]' verbunden worden), andererseits aber syrj. sizzim-das '70' (das '10'< [ran.); wog. soat-lou '70' 
(lou '10'< fiu. *luk3 > lp. lokke, loge, tscher. lu id.), s. a.a.0. 47. Somit verläuft zwischen den Zahlen 'sechs' und 'sieben' an bestimmten Stellen der fiu. Sprachfamilie gleichsam eine Scheidelinie. In einem anderen Zusammenhang weis $t$ Bergsland darauf hin, dass u.a. im Ostjaksamojedischen das Zahlwort 'sieben' auch die Bedeutung 'alle' hat; er vermutet: "At some remote time the series of strict numerals may even have stopped at 'six'", s. a.a.O. 53. Da es noch Naturvölker gibt, deren Numeralia mit sechs aufhören, erscheint dies wie auch die in gleiche Richtung gehende Folgerung von F. Kovács, dass »die finnisch-ugrischen Völker ursprünglich wohl nur ein sechser oder siebener Zahlensystem besassen" (s. ALH VHI 346), durchaus glaubhaft. Dennoch kannte das steinzeitliche fiu. Urvolk für besondere Zwecke auch grössere Gruppenzahlwörter, und zwar die auf der Gesamtzahl der Finger beruhende 10, deren Name also *luks lautete und daneben in anderen Zusammenhängen *mone, das primär 'viel' bedeutete (vgl. oben syrj. min 'zehn; viel', wog. man; NB: auch in den heutigen melanesischen Sprachen gibt es mehrere Benennungen für den Begriff 10, abhängig davon, was für Objekte gezählt werden), sowie ferner die gemeinsame Anzahl der Finger und Zehen 20 (der Vertreter des ursprünglichen Namens dieses Numerale ist ung. húsz, das Entsprechungen hat in den obugr. und perm. Sprachen und aller Wahrscheinlichkeit nach ebenfalls im Mordwinischen, wenn auch die Zugehörigkeit von mordw. kom[ə]ś in diesen Zusammenhang in letzter Zeit von einigen Forschern in Frage gestellt worden ist); man besass ferner einen eigenen Namen für die Menge $10 \times 10$ (*śata < Ar.), ja sogar für $10 \times 100$ (vgl. syrj.-wotj. surs ' 1000 ' mit seinen ugrischen Entsprechungen; auch dies ein arisches Lehnwort). Offenbar wurden die Zahlen 1-6 sowie die ihnen entsprechenden Gruppenzahlwörter 10-60, von deren Namen die meisten zusammengesetzt sind, gewissermassen als Variationen voneinander aufgefasst. Das Zählen einzelner Gegenstände scheint also mit sechs aufgehört zu haben; danach begann eine ungegliederte Vielheit, das Kollektivum. Die ugrischen Sprachen verfügen zwar über eine alte Bezeichnung für 7 , nämlich ung hét usw., doch über- 
nahm man dieses Wort vorarischen Ursprungs - nach sicher richtiger Erklärung -- erst in die ugrische Ursprache (vorar. ${ }^{*}$ septa > ugr. *septä). In den neuesten Quellen wird festgestellt, dass sich in der Folklore aller drei ugrischen Sprachen Spuren eines siebener Zahlensystems der ugrischen Zeit finden, s. "A magyar nyelv történeti-etimológiai szótár" II 101; "A magyar szókészlet finnugor elemei" 284.

Die westlichen fiu. Sprachen verfügen über eine gemeinsame Bezeichnung für 'sieben', und zwar syrj.-wotj. sizizm, tscher. šašam, šišim, mordw. śišem, fi. seitsen, seitsemän, lp. čiě̆â, (I) čičcam, das - wie seine Verbreitung bezeugt - aller Wahrscheinlichkeit nach in fi.-perm. Zeit entstanden ist. Damals erhielt das bisherige Sechsersystem als Ergänzung wenigstens das Numerale 'sieben', möglicherweise auch 'acht' und 'neun'. Nun ist die Annahme logisch, dass sich die neuen, mit sieben beginnenden Numeralkonstruktionen auf der Basis des bisher herrschenden Kollektivbegriffes entwickelten und dass sie gerade aus dem Grunde anders gebildet wurden als dic früheren Konstruktionen mit den Zahlwörtern $1-6$, so wie ein Anbau an einem alten Gebäude einen anderen architektonischen Stil haben kann als das bestehende. Wenn z.B. 'vier Fische' weiterhin wie früher entweder *neljä kala (vgl. tscher. nal kol) oder ${ }^{*}$ neljä kalat (vgl. mordw. nille kalt) hiess - beide Konstruktionen konnten meiner Vermutung nach auch nebeneinander auftreten, abhängig vom Gesichtspunkt des Sprechers (vgl. oben 6.3.9.) - so setzte man die Reihe vielleicht fort, indem man nun sagte ${ }^{*} \dot{s}(j)$, tśem kalata (Separativ), eigentlich also "sieben weg ( $\sim$ gesondert) aus der unbegrenzten, kollektiven Fischmenge». In diesem Lichte könnte der ostlappische Brauch, den aus dem Separativ entstandenen Partitiv erst mit dem Numerale $7 \mathrm{zu}$ verbinden, über das Frühurfinnische zurückgehen auf die fi.-perm. Zeit. Erst im Späturfi. hätte sich die Partitivkonstruktion analog in Verbindung mit allen Zahlwörtern über eins durchgesetzt. Ein starker Ausgleich der alten Besonderheiten - in verschiedenen Richtungen - sowie auch ihr vollständiger Schwund wäre in den wolg. und perm. Sprachen vollzogen worden. Schwache Spuren der Konstruktion Zahlwort + Separativ 
scheinen sich im Mordwinischen erhalten zu haben (vgl. oben 6.3.5.), die Numeralkonstruktionen des Tscher. und der perm. Sprachen aber kennen keinen Vertreter des Separativs, und es ist sehr fraglich, ob die genannten Sprachen überhaupt irgendeine Erinnerung an diesen uralten Kasus bewahrt haben.

9.2. Wir können nicht mit Sicherheit wissen, ob sich das Zehnersystem im eigentlichen Sinne des Wortes schon in fi.-perm. Zeit entwickelte. Die permischen Benennungen für 'acht' und 'neun', kekjà'mis und okmis, zeugen zwar von derselben Denkweise wie die entsprechenden Zahlwörter der fi.-wolg. Sprachen, also etwa $10^{--2}$ und $10-1$, entsprechen ihmen aber lautlich nicht, d.h. den Wörtern tscher. kändä $k^{x} \check{s}$,

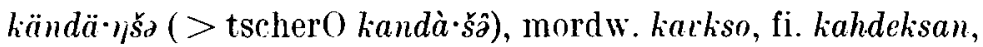

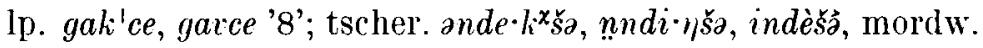
íejkse, fi. yhdeksän, lp. âk'ce, âcee (> lial. ok'ce, ovce) '9'. Die Schlusskomponente der perm. Numeralia mis gehört zu den in der Bedentung '10' verwendeten, suffixartigen Elementen, deren es in den fiu. Sprachen eine ganze Reihe gibt, vgl. J. Szinnyei FUS ${ }^{2}$ 93-94. Eine im Prinzip ähnliche Konstruktion setzt die bekannte Erklärung voraus, dass der zweite Teil der Benennungen für 'acht' und 'neun' in den fi.-wolg. Sprachen ein indoeuropäisches Lehnwort mit der Bedeutung '10' sei, nach Setäläs Rekonstruktion *deksam $\left(<\right.$ ieur. ${ }^{*}$ dek $\left.\hat{k} m\right)$. In seinen Ausführungen über die genannten Numeralia FUF XII 162-166 schildert Setälä auch die diesbezügliche Forschungsgeschichte, aus der hervorgeht, dass es D. E. D. Europaeus war, der als erster (1853) annahm, die ieur. Benennung für '10' sei in den fi.-wolg. Zahlwörtern enthalten.

Dieser Etymologie steht jedoch die Schwierigkeit im Wege, dass die Fortsetzung von ieur. ${ }^{*} k$ in einem Teil der fiu. Sprachen $(? k+)$ ein mouillierter Sibilant sein müsste. Die beweiskräftigen Sprachen Lappisch, Mordwinisch und sogar auch Tscheremissisch (nämlich $s, s$ in den Wörtern kandà $s \hat{q}$,

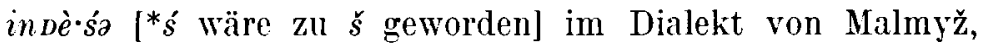
s. Setälä, a.a.O. 164; ÖDöN BEkE FUF XXII 101, 103) zeigen jedoch, dass in diesen Zahlwörtern von Anfang an ein 
nichtmouilliertes $s$ gestanden hat. Auf diese Inkonsequenz hat Hermans Jacobsohn MSFOu LXVII 147 mit klaren Worten hingewiesen. Collinder dagegen vermutet etwas überraschend, dass auf fiu. Seite in erster Linie ${ }^{*} k s ̌$ (und nicht ${ }^{*} k s$ ) anzunehmen sei, s. Vir. 1953 S. 94. Wie sicher auch die meisten anderen Forscher steht Collinder der ganzen *deksam (*teksam)-Erklärung äusserst skeptisch gegenüber. (Syrj.-wotj. das '10' ist dagegen mit Sicherheit ein Abkomme des genannten ieur. Wortes, aber aus einer späteren iran. Sprachform entlehnt.) Doch auch seine eigene Hypothese wirkt semantisch problematisch, dass nämlich die Benennungen für 'acht' und 'neun' aus den Wörtern 'zwei' und 'eins' mittels des Suffixes *ks (vgl. fi. aidalse- 'Zaunholz' < aita 'Zaun') gebildet seien; wenigstens im Tscher. habe vor $* k$ s noch ein anderes Suffix gestanden, ${ }^{*} n t$ bzw. * $n d$. In Verbindung mit diesen Ableitungen sei auch das später geschwundene Wort für 'zehn' aufgetreten, offenbar fiu. *luka.

Ewald Fetrweis zählt auf den Seiten $71-72$ seiner Arbeit "Das Rechnen der Naturvölker» eine grosse Anzahl von Sprachen auf, wo ' 8 ' und ' 9 ' folgendermassen benannt werden: "noch 2 an 10 fehlend", "noch 1 an 10 fehlend" oder wobei '10' gar nicht erwähnt wird - "lass zwei weg", "lass einen weg»; "2 nicht", "1 nicht" usw. Die den uralischen Sprachen geographisch nächste Sprache mit einem solchen Prinzip dürfte das Jenisseiostjakische oder Ketische sein, wo ' 8 ' dialektal инӓм бынсӓм heisst, wörtlich "двух не имеется (не хватает до десяти)", d.h. "zwei existieren nicht (fehlen an od. von zehn)", und '9' entsprechend кусӓм бынсӓм "eins existiert nicht", s. A. P. Dulsos "Očerki po grammatike ketskogo jazyka" I 124-125; "Ketskij jazyk» 128. Wenn man nun vermutete, dass das Negationsverb $e$-in fi.-wolg. Zeit auch eine mediale bzw. reflexive Flexion gehabt hätte, wie es noch heute beim Negationsverb einiger samojedischer Sprachen der Fall ist (vgl. M. A. Castrén "(Trammatik der samojedischen Sprachen" 435; PÉTer HaJdú "Chrestomathica Samoiedica" 72), dann hätte es gerade so flektiert selbständig 'nicht existieren' bedeuten können. Wenn weiterhin die reflexive Flexion im Prinzip jener im Ostseefinnischen (z.B. heitä-k-sen 
'er wirft sich') entsprochen hätte, die Endungen aber den Typus vertreten hätten, der mit Hilfe des Lappischen und teilweise auch des Mordwinischen und Tscheremissischen als ursprünglich nachweisbar ist (vgl. Verf., Vir. 1955 S. $169-$ 170; Studia Fennica $\mathrm{IX}_{\mathbf{3}}$ S. $13-15$ ), dann hätte veins existiert

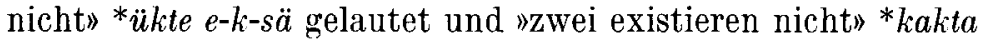
$e-k-s a ̈ n$, wo das auslautende $n$ der im Lappischen noch heute erhaltene Dualcharakter war. Aus der ersteren Wortverbindung wäre über Agglutination *ükteksä (> späturfi. *ühdeksä-) geworden und aus der letzteren in Angleichung an die Vokalharmonie *kakteksan (> späturfi. *kahdeksan). Die Annahme von dem unserer Erklärung nach als ursprüngliches Dualsuffix anzusehenden Auslaut- $n$ erfordert in diesem Zusammenhang speziell das inlautende $n$ bei den tscher. Zahlwörtern, das metathetisch in seine heutige Stellung gelangt ist (also irgendwie: frühurtscher. *käktäksan $>{ }^{*} k a ̈ n d a ̈ k s a$, usw.). Im Mordwinischen trat Synkope ein und eine beachtliche Vereinfachung der dadurch entstandenen Konsonantenhäufungen, während sich gleichzeitig der Typus *ükteksä ohne Auslaut- $n$ in beiden Zahlwörtern durchsetzte. Synkope traf auch die lappischen Wörter, deren Schwachstufigkeit der Grundform verursacht werden konnte durch das Auslaut-n, das aus dem Wort *kakteksan verallgemeinert und als Genitivendung aufgefasst wurde: ${ }^{*}$ kakteksan $>$ frühurlp. ${ }^{*} k \dot{a} \gamma_{(} \dot{t} \operatorname{sen}$

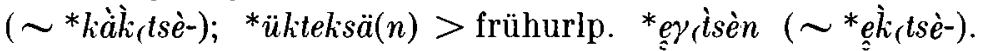
Das Ostseefinnische hat - wie üblich — die Lautgestalt der Urformen am besten bewahrt. Die Ausgleichung brachte auch hier in beide Numeralia das Auslaut-n, das stellenweise (z.B. im Finnischen) als ein der Gen.-Akk.-Endung vergleichbares Suffix aufgefasst wurde, anderwärts wiederum - gestützt auf das Wort seitsen, seitsemän - als ein zum Stamm gehörender Vertreter des urspr. $m$. (Setälä meinte denn auch, unter Hinweis auf analoge Verhältnisse wie wot. kahesāa, Gen. kahess-

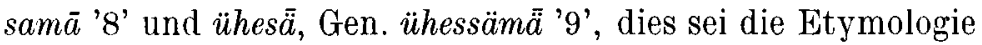
des diesbezüglichen $m$, s. YSÄH 400-402; FUF XII 165.) Es ist ganz natürlich, dass die Wortverbindungen, aus denen die Benennungen für acht und neun entstanden, als sie zu einem Wort verschmolzen, ihren verbalen Charakter weit- 
gehend einbüssten und dass die Funktion des Auslaut-n des Wortes *kakteksan unverständlich wurde (auch wenn der Dualnumerus mit $n$-Charakter in der Verbalflexion damals noch erhalten gewesen wäre). Ebenso natürlich war es, beide Wörter einander strukturell völlig anzugleichen. Im Osfi. und Lp. schlossen sich verbreitet auch die Wörter für 'sieben' und 'zehn' derselben Reihe an.

Die Behandlung der Entstehung der Benennungen für ' 8 ' und ' 9 ' bedeutet zwar eine Abweichung von meinem eigentlichen Thema, ist meines Erachtens in diesem Zusammenhang aber doch nicht ganz unmotiviert, da es sich dabei mit un die wichtigsten jener Numeralia handelt, mit denen meiner Vermutung nach zumindest schon in fi.-wolg. Zeit eine Separativ- od. Partitivkonstruktion verwendet wurde, so dass auch sie und ihre Chronologie mit der Geschichte des Partitivs eng zusammengehören.

Erkki Itkonex 